\title{
BRINGING AUTOMATIC STEREOTYPING UNDER CONTROL: IMPLEMENTATION INTENTIONS AS EFFICIENT MEANS OF THOUGHT CONTROL
}

\section{DISSERTATION}

\author{
Presented in Partial Fulfillment of the Requirements for \\ the Degree Doctor of Philosophy in the Graduate \\ School of The Ohio State University
}

By

Brandon D. Stewart, M.P.H., M.A.

$* * * * *$

The Ohio State University

2007

Dissertation Committee:

Russell H. Fazio, Advisor

Approved by

Marilynn B. Brewer

Gifford Weary

Advisor

Graduate Program in Psychology 


\begin{abstract}
Evidence of automatic racial bias raises the question of whether, and how, unintended biases initiated in milliseconds can be brought under intentional control. Past research investigating people's ability to control automatic bias has produced mixed findings. The current research tested the utility of an implementation intention, a promising strategy for reducing the effects of automatic bias on behavior. An implementation intention is an if-then plan that links an environmental cue to a specific response; it is hypothesized to automate the execution of the response intention when the cue is encountered. In the first two experiments, participants were asked to identify an object (e.g., gun or tool) after being presented with either an African American or a Caucasian face. Half of the participants formed a counter-stereotypical implementation intention to think the word, "safe", when they saw Black faces. Participants in the control condition received an implementation intention that was not associated with the relevant racial stereotype. These experiments demonstrated that automatic stereotyping was reduced only when participants had formed a counter-stereotypical implementation intention, even though all participants had been warned about being biased. A process dissociation analysis determined the separate contributions of automatic and controlled influences on task performance. The effect of the counter-stereotypical intention on
\end{abstract}


stereotyping occurred via a reduction in automatic stereotype bias and not differences in controlled thinking (Experiments 1 and 2). This was the first demonstration of automatic bias being reduced in this weapon identification paradigm. Experiment 2 showed that this benefit was acquired with little practice and it generalized to novel faces (i.e., photos of Black faces that had not been presented during the intention rehearsal phase).

Experiments 3 and 4 examined another consequence of the counter-stereotypical intention, the possibility that it may reduce visual attention to objects associated with the intended social category. In these experiments, a dot-probe methodology revealed that a counter-stereotypical implementation intention reduced visual attention to stereotypecongruent objects after participants had seen a Black individual. Overall, these four experiments demonstrated that an implementation intention may be an effective and efficient means for controlling automatic aspects of thought and for controlling visual attention. 


\section{ACKNOWLEDGMENTS}

I wish thank my advisor, Russ Fazio, for supporting the continued development of this research and for his excellent advice during the revision process.

I thank Keith Payne for collaborating on the original development of this research idea and on the initial studies and manuscript drafts.

I am grateful to members of the Social Cognition Research Group and the Fazio

lab for interesting discussions and helpful feedback during numerous presentations of this work.

Finally, I would like to thank my spouse, Karen, for her patience, understanding, guidance, and love during my progress toward this and other goals. 
VITA

June 9, 1973.

Born - Mitchell, SD

1995

B.S., Biology, Nebraska Wesleyan University

1997

M.P.H., Community Health Education, University of Massachusetts

M.A., Psychology, The Ohio State University

$1998-2000$

Research Analyst, University of Massachusetts Donahue Institute

$2000-2001$

University Graduate Fellowship, The Ohio State University

$2001-2002$

National Institute of Mental Health Predoctoral Traineeship,

The Ohio State University

2002 - present

Graduate Teaching and Research Associate, The Ohio State University

\section{PUBLICATIONS}

Research Publications

1. Payne, B. K., \& Stewart, B. D. (2007). A process dissociation approach to automaticity and control. In J. A. Bargh (Ed.) Social psychology and the unconscious: The automaticity of higher mental processes. Psychology Press. 
2. Weary ${ }^{1}$, G., Vaughn ${ }^{1}$, L. A., Stewart ${ }^{1}$, B. D., \& Edwards, J. A. (2006). Adjusting for the correspondence bias: Effects of causal uncertainty, cognitive busyness, and causal strength of situational information. Journal of Experimental Social Psychology, 42, 8794.

3. Payne, B. K., Cheng, C. M., Govorun, O., \& Stewart, B. D. (2005). An inkblot for attitudes: Affect misattribution as implicit measurement. Journal of Personality and Social Psychology, 89, 277-293.

\section{FIELDS OF STUDY}

Major Field: Psychology 


\section{TABLE OF CONTENTS}

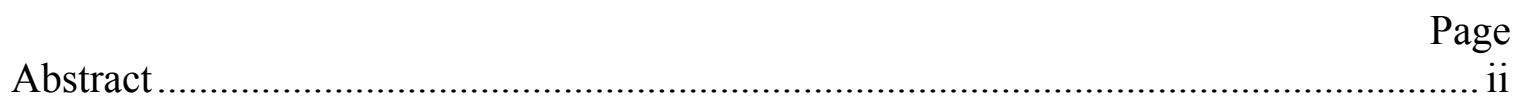

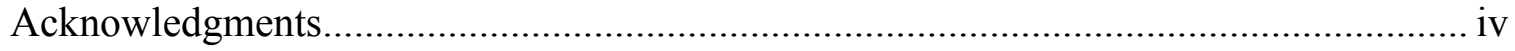

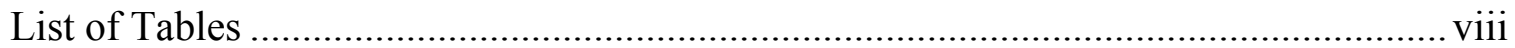

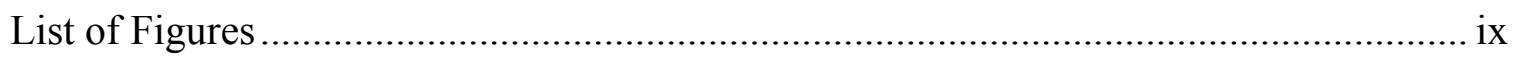

Chapters:

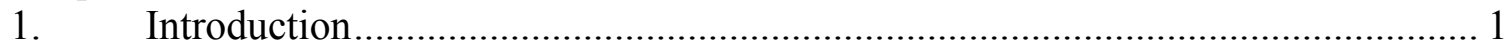

2. Experiment 1: Reducing Automatic Bias ................................................. 14

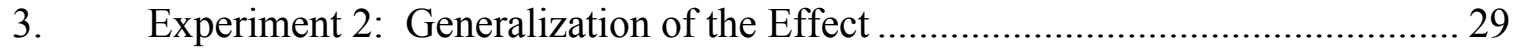

4. Experiment 3: Altering Visual Attention.................................................. 39

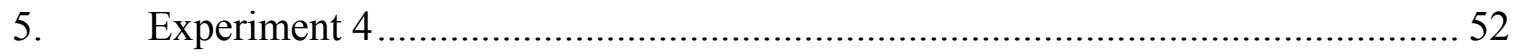

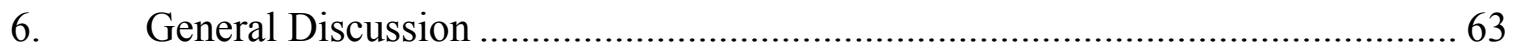

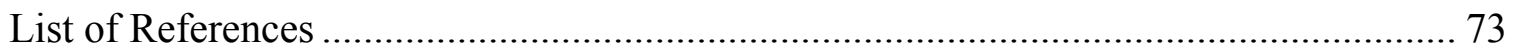

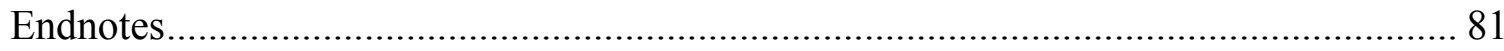

Appendices:

Appendix A: Materials used in Experiment 1 .................................................... 82

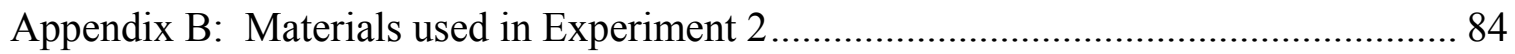

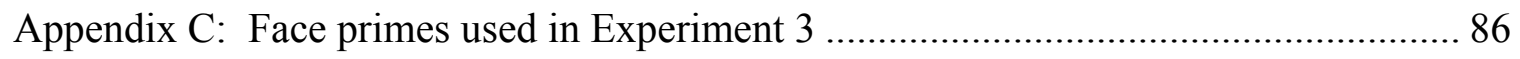

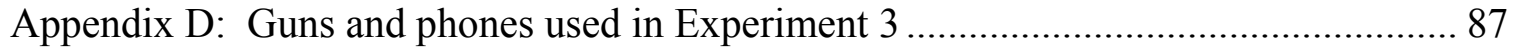




\section{LIST OF TABLES}

Table Page

2.1 Automatic Estimates by Prime and Implementation Intention.............. 24

2.2 Cognitive Control Estimates by Prime and Implementation Intention......... 25

3.1 Automatic Estimates by Prime and Implementation Intention............. 36 


\section{LIST OF FIGURES}

Figure

2.1 Proportion of errors by type of Object error (false "gun" versus false "tool" response), Race prime (White versus Black), and Implementation intention condition (counter-stereotypical versus control) .........................

3.1 Proportion of errors by type of Object error (false "gun" versus false "tool" response), Race prime (White versus Black), and Implementation intention condition (counter-stereotypical versus control) .........................

3.2 Stereotypical performance bias as a function of Block and Implementation intention condition (counter-stereotypical versus control).

4.1 Reaction time (re-transformed to milliseconds from log transformed means) as a function of the Race prime (Black or White) and Dot position (after a gun or a phone), and Implementation intention condition (counterstereotypical versus control)

5.1 Reaction time (re-transformed to milliseconds from log transformed means) as a function of the Race prime, Dot position (after gun or phone), Implementation intention condition (counter-stereotypical versus control), and the $250 \mathrm{~ms}$ condition.

5.2 Reaction time (re-transformed to milliseconds from log transformed means) as a function of the Race prime, Dot position (after gun or phone), Implementation intention condition (counter-stereotypical versus control), and the $250 \mathrm{~ms}$ condition. 


\section{CHAPTER 1}

\section{INTRODUCTION}

People sometimes do one thing when they intend to do another. These conflicts between thought and action usually occur because aligning actions with intentions requires ability and motivation, which are all too often in short supply. Distractions, fatigue, or other demands may limit people's ability and motivation and thus their control. In the absence of this intentional control, it is an important fact that we do not act randomly. We rely instead on well-learned habits, categories, or highly accessible thoughts (Bargh, 1999; Ouellette \& Wood, 1998).

These well-worn habits of thought and action are often useful and adaptive.

Sometimes, however, accessible habits can interfere with goals. For example, we may try not to use stereotypes when meeting someone new at a party. Yet, when nervousness or distraction disrupts our intentions, we use them anyway, saying things that leave us as puzzled and uncomfortable as the person we just pushed neatly into a pigeonhole.

In this and other examples, avoiding or overcoming automatic thinking is an essential component of achieving goals and avoiding unwanted biases. The influence of conscious goals in moderating automatic stereotyping and related biases has become an important focus of research in stereotyping and in automaticity more generally (Bargh, 
1999; Blair, 2002; Kunda \& Spencer, 2003). A primary theoretical issue at stake is whether psychological effects deemed to be "automatic" also should be considered uncontrollable. Research to date has provided mixed evidence. Here I briefly review some key points in this debate and then present new data bearing on whether, and under what circumstances, people can moderate their own automatic stereotype biases. I tested a special type of conscious control strategy, an implementation intention, to see whether it reduced automatic stereotyping, increased controlled thinking, or affected both.

\section{Malleability and Stereotyping}

There is little doubt that people have a great deal of control over their behaviors when they have ample motivation and opportunity to engage in careful and thoughtful action (for review, see Fazio \& Towles-Schwen, 1999; Fiske, Lin, \& Neuberg, 1999). The question of interest here is instead about more subtle, implicit forms of stereotyping that are likely to take place when it is difficult to monitor and control responses.

Early research on implicitly-measured attitudes and stereotyping led researchers to conclude that automatic biases were likely to be very rigid, and require arduous learning processes to change. More recent research has found that implicit measures of stereotyping may be quite malleable in response to contextual factors (for review, see Blair, 2002; Dasgupta \& Greenwald, 2001; Kawakami, Dovidio, Moll, Hermsen, \& Russin, 2000; Mitchell, Nosek, \& Banaji, 2003; Wittenbrink, Judd, \& Park, 2001). In particular, performance on implicit measures has been shown to be moderated by a variety of factors including: 1) the context surrounding the stimulus (Barden, Maddux, Petty, \& Brewer, 2004; Lowery, Hardin, \& Sinclair, 2001; Sinclair, Lowery, Hardin, \& 
Colangelo, 2005; Wittenbrink et al., 2001), 2) situationally activated self-enhancement motives (Spencer, Fein, Wolfe, Fong, \& Dunn, 1998; Sinclair \& Kunda, 1999), 3) focus of attention (Macrae, Bodenhausen, Milne, Thorn, \& Castelli, 1997), 4) effortful practice (Kawakami et al., 2000) and 5) promotion of counterstereotypes (Blair, Ma, \& Lenton, 2001). There is little doubt that implicit measures of bias can be moved. It is much less clear, however, whether one's own conscious intentions can be the primary mover.

\section{Malleability and Intentional Control}

The studies reviewed previously have raised optimism that stereotyping might be more amenable to volitional control than previously thought. After all, if implicit measures are sensitive to mental images and varying situations, shouldn't they be responsive to participants' efforts to overcome bias? It is probably too soon, however, to equate situational malleability with controllability. In fact, there is mixed evidence on whether people's intentions, rather than the passive influence of context, can moderate automatic stereotyping. Some of the experiments that have manipulated people's awareness of stereotyping and active attempts at controlling automatic stereotyping have tended to show "backfire" effects, while some others have found positive effects. One study found a decrease in race stereotyping measured with the IAT when participants had a goal to avoid bias and the experimenter was African American (Lowery et al., 2001); the explanation proposed was that participants automatically "socially tuned" toward the attitudes of the experimenter. This study suggested that the status or liking of the African American partner must be high for this effect to be observed. 
Several other studies, in contrast, have shown increased stereotyping on later tasks when participants have the conscious goal to change their responses (Galinsky \& Moskowitz, 2000; Liberman \& Foerster, 2000; Macrae, Bodenhausen, Milne, \& Jetten, 1994; Oe \& Oka, 2003). In one study, participants who were directly warned to avoid stereotype bias while performing an implicit task showed increased bias on that task (Payne, Lambert, \& Jacoby, 2002). Similar counter-intentional effects have been shown when the motivation to control stereotypes was more subtle, such as the pressure imposed by actual social interactions (Lambert et al., 2003; Richeson \& Shelton, 2003; Richeson et al., 2003). At least in some situations, it appears that attempts to control automatic stereotyping may actually set people on a path toward stereotyping, especially when control is difficult to achieve.

Because controlling automatic impulses can be difficult, it is important to identify effective strategies for avoiding bias that people can employ on demand. It is especially beneficial to identify strategies that can be used with little effort, given the added difficulty of meeting all conditions for correcting bias once it has occurred (i.e., awareness of bias, its direction and magnitude, and the motivation and ability to correct; Wilson \& Brekke, 1994). Although some studies have demonstrated that conscious strategies can moderate automatic stereotyping, these strategies are not without limitations.

One study showed that implicit task performance could be altered by spending five minutes imagining a counter-stereotypical person (e.g., strong woman; Blair et al., 2001). Participants who completed the counter-stereotypical mental imagery showed less automatic stereotyping across a variety of implicit measures. While this strategy reduced 
stereotyping, the mechanisms for this effect remain unclear. Participants may not have been aware of trying to avoid bias or control stereotyping, which often ironically induces people to stereotype. The question of whether this malleability provides evidence for controllability remains open.

Another study, in which implicit biases were altered, is especially relevant to the present studies. Blair and Banaji (1996) had participants complete a task in which they classified names as male or female when those names were preceded by stereotypical trait primes. These primes were either consistent or not consistent with the gender stereotype (e.g., aggressive-Mike; flowers-Tom). Participants showed less stereotypical associations when they had been informed to expect the stereotype-inconsistent combination. Although this finding is encouraging, it leaves several questions. First, this effect was driven mostly by the large increase in stereotyping when participants had stereotype-consistent expectations. Second, the primes in this experiment were trait and object words associated with gender stereotypes, and not category primes per se. So, strictly speaking, the findings concern whether gender is activated in response to a given word (e.g., "skirt" activating "female") and not the activation of stereotypic associations upon exposure to gender identity. Finally, the design of these experiments altered the contingencies between prime and target pairs. There was a greater percentage of counterstereotypical pairings in the stereotype-inconsistent expectation condition than in the stereotypical expectation condition. Because people are very sensitive to this kind of covariation, participants may have learned this covariation and then been quicker in responding to counter-stereotypical pairs within the experimental context (Lewicki, Hill, \& Czyzeska, 1997; Barker \& Andrade, 2006). A reduction in stereotyping could thus 
have been due to the disproportionately greater number of stereotype-inconsistent pairs rather than to intentions or expectations.

\section{Current Research}

Efficient goal pursuit with implementation intentions. The present research seeks to better understand when strategic attempts at controlling bias will be successful, and what cognitive processes are required. Past research suggests that a certain strategy, an implementation intention, may be promising because it may allow people to "automate" goal pursuit (Brandstatter, Lengfelder, \& Gollwitzer, 2001; Gollwitzer \& Sheeran, 2006). Implementation intentions are if-then, action plans (e.g. "When I leave work, I will go exercise at the gym") that have been shown to help people enact their goals more efficiently than general intentions (e.g., "I will exercise more") (Brandstatter et al., 2001; Gollwitzer \& Brandstatter, 1997). Implementation intentions have been shown to function by increasing the strength of association between the environmental cue (i.e., the "if" portion) and the goal-directed response, and by making both the environmental cue and the goal-directed response more accessible (Aarts, Dijksterhuis, \& Midden, 1999; Webb \& Sheeran, 2007). Once a person has made the initial "if-then" intentions, these intentions require little motivation and effort to employ (Brandstatter et al., 2001). In contrast, general intentions are proposed to make the intention accessible, but not in response to the relevant environmental stimulus. Thus, general intentions would not produce spontaneous if-then implementation intentions and may not produce the intended response efficiently. 
Some research has begun to show that implementation intentions may reduce automatic stereotyping on reaction time measures, at least under specific conditions (Gollwitzer \& Schaal, 1998; Gollwitzer, Fujita, Oettingen, 2004). In this research, Gollwitzer and colleagues asked participants to complete a Stroop task in which 2 male names, 2 female names, and control letter strings were presented as primes, followed by target words (gender-stereotypical and gender-neutral attributes) that were presented in four different colors. One group of participants was assigned a goal intention to judge the women in a non-stereotypical manner and others were assigned simple intentions about how they would respond when they encountered a specific name (i.e., "And, whenever I see Ina, I will ignore her gender!"). Creating an intention to ignore gender in response to a specific individual reduced automatic activation of gender on the Stroop task (i.e., no delays in color-naming on gender-stereotypical words).

While this research is promising, I see two limitations that, if overcome, would greatly expand the breadth and utility of this approach. First, the implementation intentions used were limited to one specific person from the category (e.g., "And whenever I see Ina, I will ignore her gender!). This specificity could be problematic because it may just change the response to a specific individual and not change responses to the category as a whole. Although it may be helpful to avoid stereotyping Ina, it would be more broadly useful if people could change stereotypic responses to the whole category.

Second, the implicit and explicit measures used in previous research are assumed to be process pure and to tap automatic and conscious processes, respectively. However, implicit and explicit tasks are not likely to reflect purely automatic processing (Jacoby, 
1991; Payne, Jacoby, \& Lambert, 2004; Roediger, 1990). For example, if people are uncertain about how to respond to a question on a self-report measure, they may answer with whatever comes to mind first; thus, more automatic processes can drive responses on an explicit measure. The converse also can occur when controlled processing influences performance on implicit measures. In a word stem completion measure, people may respond with whatever comes to mind first. However, if nothing comes to mind, they may intentionally search their memory for a word that fits the stem. As a result, both automatic and controlled thinking may influence the responses that are assessed. In other words, changes in implicit task performance do not necessarily reflect changes in underlying automatic processing.

Critically, in the previous research showing that implementation intentions can modify performance on an implicit task, there remains uncertainty as to whether implementation intentions functioned, a) by reducing the automatic influence of stereotypes, b) by increasing the amount of attention or concentration (i.e., controlled thinking) used during the tasks, or c) by both processes.

Separating automatic and controlled influences. Research using methods that can estimate the levels of automatic and controlled responding on a task has shown that performance on implicit tasks is due to both automatic and controlled thinking (Jacoby, 1991; Hense, Penner, \& Nelson, 1995; Payne, 2005). This dual influence of automatic and controlled thinking on implicit tasks is relevant to both the previously reviewed research on implementation intention and to interpreting research on the moderation of automatic stereotyping (Blair, 2002; Blair \& Banaji, 1996; Kawakami et al., 2000). It 
therefore becomes important to seek converging evidence from multiple approaches, including ones that do not rely on task dissociations such as finding different results on implicit and explicit measures. The process dissociation procedure is such an approach that provides an alternative to relying on task dissociations to identify automatic and controlled processing (Jacoby, 1991).

The process dissociation procedure (PDP) is able to estimate the contributions of automatic and controlled thinking to a single behavior. It accomplishes this differentiation by pitting intentionally controlled thinking against automatic thinking within a single task. Within this procedure, a process is considered automatic if it drives behavior whether it was intended or not. Intentional control is measured as the difference between performance when a person intends to respond a certain way, and performance when the person intends not to respond in that way. To the extent that people can produce a particular response when they intend to, and not produce that response when they intend not to, they are exercising control.

The process dissociation estimates of automatic and controlled influences on stereotyping have been validated in a number of previous studies using a weapon identification task. In this task, participants are primed with a Black or White face for 200 ms, and then are shown an object, either a hand gun or a tool, for a very short amount of time (100 ms). Their job is to identify quickly and accurately whether they saw a gun or a tool. In research using this task, the automatic estimate was shown to be responsive to the race of the faces, whereas the control estimate was not. Black faces led to greater bias to respond gun. In contrast, the control estimate was reduced by speeded responding and by depletion of self-regulation resources whereas the automatic estimate was not (Govorun 
\& Payne, 2006; Payne, 2001). In these experiments, both automatic and controlled thinking contributed to performance on the weapon identification task, and these types of thinking were influenced in the expected manner by manipulations that were believed to influence either automatic or controlled thinking. Stereotypical primes increased the automatic bias estimate, whereas time pressure and cognitive resource depletion reduced the control estimate. A different set of experiments also demonstrated the convergent and discriminant validity of the estimates. The automatic estimate, reflecting automatic influences of race primes, was moderately correlated with implicit measures of racial attitudes, but not with a measure of attentional control; thus, the automatic estimate seems to tap some of the same construct that the implicit measures tapped. The control estimate, however, was uniquely correlated with a measure of attentional control, and not with the implicit measures of attitudes (Payne, 2005).

The separate influence of automatic and controlled thinking on a single behavior has important consequences for controlling behavior. For example, research has shown that participants differ in their level of control (i.e., ability to respond as intended), and that those with low levels of control were more influenced by automatically activated stereotypes (Payne, 2005). Such increased influence of stereotypes due to decreases in controlled thinking have also been produced experimentally by inducing nervousness through either an anticipated public appearance or an actual interracial interaction (Lambert et al., 2003; Richeson \& Trawalter, 2005). Given that Process Dissociation estimates have proven to be valid measures of automatic and controlled influences, my aim in the present research was to use them to clarify how implementation intentions have their impressive effects. 
Overview of Experiments

Consider the sequence of events that unfolds very quickly when a person sees someone with an object, and tries to determine whether the object is a threat. People may spontaneously categorize other people on at least a few key dimensions such as sex, race, and age (Macrae \& Bodenhausen, 2000). Within a few hundred milliseconds, then, the perceiver may be reacting differently to a young Black man than to an older White woman, or even to a young White man. The thoughts and feelings associated with these social categories are activated, potentially leading to stereotypical and prejudicial responses. At the same time, the perceiver also is focusing attention on the object, trying to discern what it is, and trying to respond appropriately. One stream of informationstereotypical thoughts and feelings - could lead to an assumption that the object was dangerous regardless of what it truly is. The second stream of information - selective attention to the features of the object - would lead to correct responding regardless of who the person is. The perceiver's ultimate behavior depends on the quick resolution of these potentially different inclinations.

Consider now the response of a perceiver who has made a specific plan for what to think before the encounter. According to research on implementation intentions, people can carry out goals quickly, efficiently, and relatively effortlessly by identifying a specific cue and a specific goal-appropriate action in an if-then format. In the present example, stereotypic thoughts and feelings of threat, criminality, and danger are the link between race and weapons. To counter this stereotype, I might have the perceiver think its opposite, "safe." Having previously decided to respond to African Americans by 
simply thinking the thought, "safe," the chain of events might change drastically. If the implementation intention is effective, then upon categorizing the person as a young Black man, thoughts of safety would be activated instead of thoughts and feelings of threat that are associated with the cultural stereotype.

It is an open empirical question whether such an implementation intention would be effective. I hypothesized that it could be. It is also an open question whether it might have its effects by changing the automatic influences of race on judgments, or by boosting intentional control over responses. The counter-stereotypical implementation intention to think "safe" may inhibit the activation of the stereotype (i.e., one stream of information), which would allow people's current level of control to exert more influence on their response of identifying the object held. Alternatively, the intention may also increase people's focus on the objective features of the object (i.e., the second stream of information noted above), which would increase their control (i.e., ability to respond accurately as intended). Furthermore, it is possible that an implementation intention of this sort could have unintended consequences by simply creating a new counterstereotypical race bias. The think "safe" implementation intention may cause participants to simply respond "tool" whenever they see a Black face; this would create a counterstereotypical response pattern in which there are more tool responses after Black faces than White faces. I measured automatic and controlled influences on behavior and used two different measurement methods to answer these questions.

The current research extends previous work on moderation of stereotyping and work on implementation intentions in two major ways. First, I used multiple behavioral methods: a weapon identification task that could be examined by using the Process 
Dissociation Procedure, and a probe detection task that provided information about attentional bias in visual processing. By not relying solely on a global measure of implicit task performance, I was able to test the extent to which implementation intentions affected automatic and controlled components separately. Second, previous research has shown that behavioral implementation intentions are very specific to the particular exemplars included in the If-Then intention. I examined whether implementation intentions could be more broadly effective by extending them to an entire social category and determining how much practice was required to use them.

In the first two experiments, I used a behavioral measure and process dissociation analysis to test whether counter-stereotypical implementation intentions reduced stereotyping and whether the reduction occurred primarily through a lessening of automatic stereotyping, an increase in controlled thinking, or a combination of the two. I also tested whether the intentions extended to an entire social category and not just exemplars. Finally, I began to examine other consequences of the implementation intentions, such as the possibility that they may reduce visual attention to objects associated with the social categories. Two additional experiments employed a dot-probe methodology to illuminate this influence of implementation intentions on the processing of visual information related to the stereotype. 


\section{CHAPTER 2}

\section{EXPERIMENT 1: REDUCING AUTOMATIC BIAS}

In Experiment 1, I sought to restrict participants' ability to control responses to a great degree and to determine the separate influences of automatic stereotyping and controlled thinking in the reduction of stereotyping. This experiment used a weapons identification task because it greatly restricts control and because process dissociation can be used to estimate the influences of automatic and controlled responding (Payne, 2001; Payne et al., 2002). An additional strength of the weapon identification task is its use of multiple criteria for assessing automaticity - including a short stimulus-onset asynchrony, speeded responses, and process dissociation analysis.

The method used by Payne et al. (2002) will be described now because it forms the basis for my use of the process dissociation procedure in this experiment. Payne et al. asked participants to complete a weapons identification task under a response deadline of $450 \mathrm{~ms}$. Participants were asked to identify an object (i.e., hand gun or hand tool) shown for $100 \mathrm{~ms}$ immediately after being primed with either an African American or a Caucasian face for $200 \mathrm{~ms}$. Participants showed increased automatic stereotyping (e.g., mistakenly responding "gun" to a tool when primed with a Black face) regardless of whether they had a goal to "use race" or "avoid using race" compared to a no-goal, control group. 
Within the process dissociation procedure, a response is considered automatic if it causes behavior whether that behavior was intended or not. In the weapon identification task, automatic bias is seen as a tendency to respond in a stereotypical way when a person is unable to respond as intended or to exert control over responses (e.g., respond "gun" when primed with a Black as opposed to a White face, and the actual object was a tool). The automatic stereotyping estimate in this task can be characterized as an estimate of automatic processing because it (a) occurs rapidly, and (b) occurs despite intentions to the contrary (Payne et al., 2002). The cognitive control estimate may be conceptualized here as the ability to respond as intended (i.e., accurately identify the object based on the objective features of the stimulus and the task goals) without bias from stereotypes. The control estimate can be characterized as controlled thinking because it (a) is defined by the ability to respond in accordance with explicit task goals, and (b) is sensitive to the manipulation of processing resources. In the weapon identification task, a person with high control will be able to discriminate between guns and tools well.

The guns and tools presented within the weapon identification task are clear and easily identifiable. This absence of ambiguity makes it unlikely that stereotype-congruent misidentifications are due to an enduring illusion in which a participant would believe he or she saw a gun after seeing a Black face when, in fact, a tool was shown. A pair of experiments support the idea that stereotype-congruent misidentifications of weapons are due, instead, to a failure of cognitive control (i.e., unable to exert control over responses). In the first experiment, confidence ratings were taken immediately after each gun/tool response (Payne, Shimizu, \& Jacoby, 2005). When participants responded correctly, their subjective confidence in being correct was high. When they responded incorrectly, their 
subjective confidence was low. Thus, participants did not believe that they were accurate when they had made mistakes. These results are inconsistent with an enduring illusion hypothesis because this hypothesis suggests that participants would believe they were accurate when they had made stereotype-congruent mistakes. In a second experiment, participants responded by identifying whether the presented object had been a gun or a tool, and they did so under time pressure. After each response, they were allowed to respond a second time, which allowed them to correct any mistakes they believed they had made. Participants made stereotype-congruent errors on the time-pressured responses, but made far fewer errors on the non-time-pressured responses. The enduring illusion hypothesis is ruled-out because it suggests a different pattern in which participants continue to make stereotype-congruent errors on the non-time-pressured trials.

In Experiment 1, I used the weapon identification task to restrict participants' ability to use controlled thinking to reduce stereotypical responses, and I used the process dissociation procedure to estimate the influence of automatic bias and controlled thinking on performance. Participants completed 192 trials in which they were asked to identify whether an object was a gun or a tool, after being primed with Black or White faces. Half the participants received a counter-stereotypical implementation intention (i.e., think "safe" when they saw a Black face) while the other half received a control intention (i.e., think "quickly"). I predicted that those participants receiving the counter-stereotypical intention would show less stereotyping, and that the reduction would be due to a decrease in automatic bias. 


\section{Method}

Participants. Seventy participants (41 female, 29 male) from introductory psychology courses participated for course credit.

Design and Procedure. The experiment used a 2 (Implementation intention: counter-stereotypical or control) x 2 (Race prime: African American or Caucasian face) x 2 (Object: hand gun or hand tool) design with race prime and object as within-participant factors. Participants were informed that the experiment concerned how people make simple but quick decisions. They were told that they would see pairs of pictures flashed one after the other. The first picture would be a face. Initially, participants were told that they should do nothing with the face because it was simply a warning signal that the second image was about to appear. Participants then were told that the second image would be an object and their job was to identify the object as quickly and accurately as possible; thus, all participants had a general goal to respond quickly and accurately. A second screen then appeared, informing them that they should judge what each object is by pressing the "Gun" or "Tool" key on the keyboard. Participants completed 32 practice trials to become acquainted with the task, before the critical trials began. On each trial, a message appeared that asked them to respond more quickly if they had responded too slowly.

The weapon identification task exposed participants to pairs of pictures. The first picture (the prime) included black and white photographs $(5.3 \mathrm{~cm} \mathrm{x} 4 \mathrm{~cm})$ of four African American male and four Caucasian male faces (Appendix A). The second picture (the 
object) was either a hand gun or a hand tool (Appendix A). The prime remained on the screen for $200 \mathrm{~ms}$ and it then was replaced by the object for $100 \mathrm{~ms}$. Thus, the stimulus onset asynchrony (SOA) was $200 \mathrm{~ms}$. After the object was presented, it was replaced with a visual mask that remained on the screen until the participant responded. As in previous research, participants were warned to respond more quickly if their response was longer than $450 \mathrm{~ms}$ (Payne et al., 2002). For each trial, the prime appeared $500 \mathrm{~ms}$ after the previous response.

Following the basic instructions and practice trials, participants received the implementation intention manipulation. All participants were warned that the race of the face (African American or Caucasian) impacts the way that people classify the second object (a gun or tool). They then were informed that, "Studies on perceptual readiness have shown that a certain mental exercise helps increase one's reactivity. If you make a resolution to respond in a particular way to a specific type of face, you will be able to change your reaction;" this instruction was modeled after implementation intention instructions used by Brandstatter et al., 2001. Next, participants were shown four cards on the computer monitor and were asked to "Choose the type of face you will respond to by pressing the 1,2,3, or 4 key." All participants were told that they had selected to respond to African American faces. This card-selection procedure was used because previous research has shown that giving participants a feeling of choice increases commitment to the goal (Burger \& Cornelius, 2003; Kiesler, 1971).

The instructions for each condition diverged at this point. Participants in the counter-stereotypical implementation intention condition were told, "In order to firmly commit yourself to responding to the Black face by thinking 'safe', please say to yourself 
silently, I definitely want to respond to the Black face by thinking, 'safe'." Past research has used an identical format to provide participants with implementation intentions (Brandstatter et al., 2001) $)^{\frac{1}{}}$. The word safe was chosen for the thought because it is counter to the stereotypes that link African Americans to weapons in this task (e.g., dangerous, hostile, and criminal).

Participants in the control condition were told, "In order to firmly commit yourself to responding to the Black face by thinking 'quickly', please say to yourself silently, I definitely want to respond to the Black face by thinking, 'quickly'.” The think "quickly" implementation intention was a task-relevant thought, but was not associated with tools or weapons. I therefore expected that it would not interfere with the task of classifying objects accurately. Furthermore, all participants were asked to respond quickly and accurately as part of the task instructions.

Participants completed 192 critical trials of the weapons identification task divided into three blocks of 64 trials each. Prime-object pairs were presented in random order and all possible pairings were included.

Results

The main dependent measure of interest was the analysis of errors: the misidentification of tools as guns, and of guns as tools. A 2 (Implementation Intention: counter-stereotypical or control) x 2 (Race Prime: African American or Caucasian) x 2 (Object: gun or tool) repeated measures ANOVA, with race prime and object as repeated measures, was performed on the error rates. I observed the expected Race prime $\mathrm{x}$ Object interaction in which participants falsely identified a tool as a gun more often after being 
primed with a Black compared to a White face, and falsely identified a gun as a tool more often after a White face, $F(1,68)=11.25, p=.001$. This pattern represents stereotypic responding.

As expected, the two-way interaction was qualified by an Implementation intention $\mathrm{x}$ Race prime $\mathrm{x}$ Object interaction, $F(1,68)=5.32, p=.024$ (Figure 2.1 on page 21). Participants in the control intention condition showed a significant stereotyping pattern, Race prime x Object interaction, $F(1,31)=21.36, \mathrm{p}<.001$, but those in the counter-stereotypical condition showed no evidence of stereotyping, Race prime x Object interaction, $F<1$. 


\section{Control Intention}

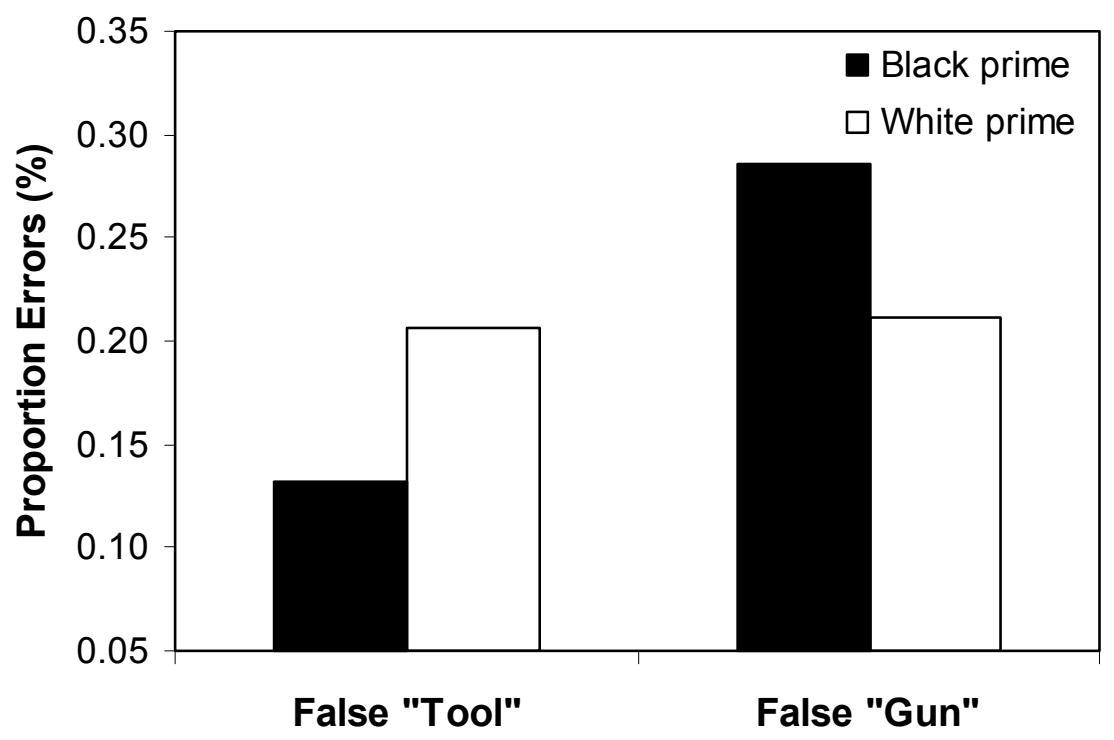

Counter-stereotypical Intention

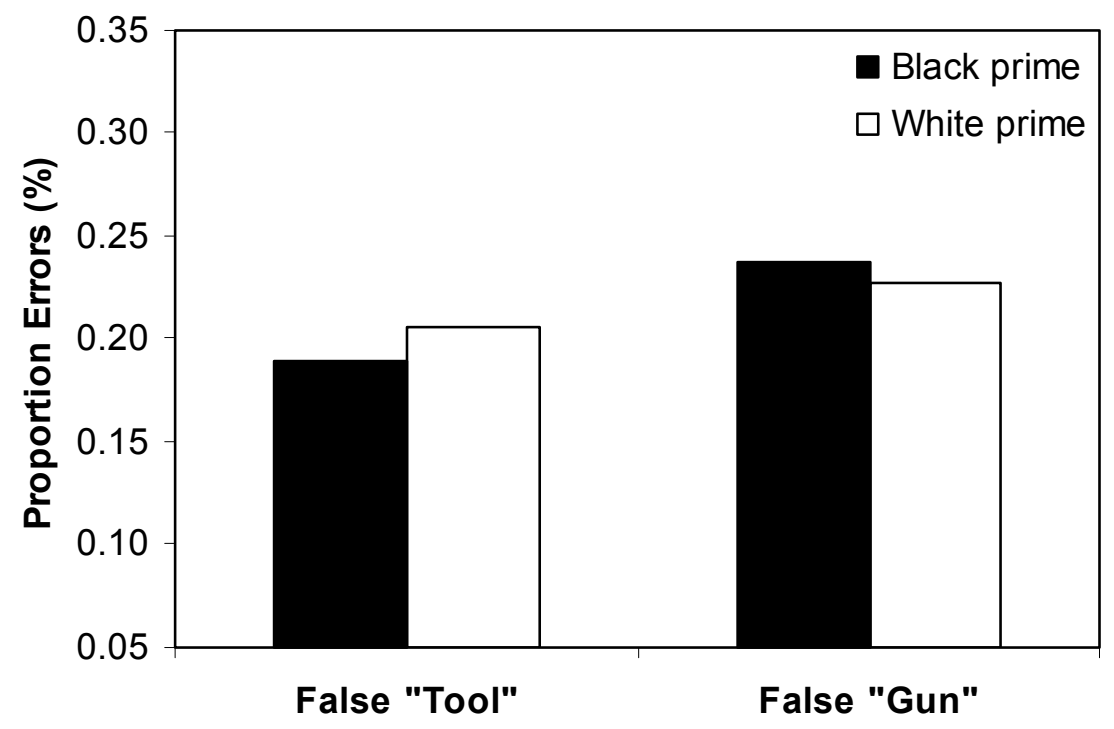

Figure 2.1: Proportion of errors by type of Object error (false "gun" versus false "tool" response), Race prime (White versus Black), and Implementation intention condition (counter-stereotypical versus control). 
I next investigated whether the reduction in stereotyping that was observed in the counter-stereotypical condition was due to responses becoming less stereotypical after Black primes. To examine this possibility, I conducted separate Intention x Object repeated measures ANOVAs for each type of prime. For White prime trials, there was a non-significant Intention $\mathrm{x}$ Object error interaction, $F<1$. The false "tool" errors and false "gun" errors were equivalent in the control and counter-stereotypical intention conditions. This lack of a difference indicated that the counter-stereotypical intention did not alter responses to White primes. However, for Black prime trials, there was a significant Intention $\mathrm{x}$ Object error interaction, $F(1,68)=6.59, p=.012$. Participants in the counter-stereotypical intention condition showed fewer stereotypical errors (e.g., False "gun" errors) on Black prime trials; thus, it appears that the effect of counterstereotypical intentions was limited to the Black faces to which participants had formed their intentions.

\section{Estimating automatic bias and controlled processing}

The design of this weapon identification experiment allowed me to use process dissociation to estimate the influence of automatic (A) and controlled thinking (C) on responses, as was done in Payne (2001). The weapon identification task included both congruent conditions, in which automatic stereotyping and controlled thinking act in the same direction, and incongruent conditions, in which they oppose one another. In a congruent condition, responding either on the basis of the actual object shown $(\mathrm{C}=$ control) or responding on the basis of the racial category ( $\mathrm{A}=$ automatic stereotypic associations) in the absence of control will lead to a correct response. This relationship 
may be expressed mathematically in the following equation: $\mathrm{P}($ correct $\mid$ congruent $)=\mathrm{C}$ $+\mathrm{A}(1-\mathrm{C})$. Therefore, the probability of responding correctly on congruent trials is the probability of controlled thinking, C, plus the probability of an automatic association when control fails, $\mathrm{A}(1-\mathrm{C})$.

In an incongruent condition, automatic influences and controlled thinking should lead to contradictory responses. Stereotypical errors will result to the extent that control fails, and people respond based on the activated stereotype. Mathematically, this can be written as the $\mathrm{P}($ stereotypic error $\mid$ incongruent $)=\mathrm{A}(1-\mathrm{C})$. The two sets of equations then may be used to derive estimates of each process. Control is solved algebraically as the difference between correct responses in the congruent condition, and errors in the incongruent condition: $\mathrm{C}=\mathrm{P}($ correct $\mid$ congruent $)$ - $\mathrm{P}$ (stereotypic error $\mid$ incongruent $)$. It amounts to subtracting false "gun" responses after seeing a Black face and a tool, from the true "gun" responses after seeing a Black face and a gun. Control will be high if people can respond as intended (i.e., based on the actual object seen) and avoid stereotypic errors; if participants respond "tool" only when they see a tool and respond "gun" only when they see a gun, then their control estimate will be high. Given the estimate of control, one can solve for the automatic stereotype bias estimate. This automatic bias is equal to the probability of stereotypical errors in the incongruent condition divided by failures to control: $\mathrm{A}=\mathrm{P}($ stereotypic error $\mid$ incongruent $) /(1-\mathrm{C})$.

I used the previous PDP formulas to derive the automatic estimate: higher numbers for the automatic estimate represent a greater bias toward responding "gun". Automatic stereotyping is observed when automatic bias is higher after a Black prime than after a White prime. A repeated measures ANOVA on automatic bias with race 
prime as a within-participant factor and implementation intention as a betweenparticipant factor revealed an Implementation intention $x$ Race prime interaction, $F(1,68)$ $=3.91, p=.052$. Simple effects tests found evidence of stereotyping in the control intention condition because automatic bias was significantly higher after Black primes than after White primes $(M=.68, S D=.17 ; M=.52, S D=.19$; Table 2.1). This automatic stereotyping was eliminated in the counter-stereotypical intention condition ( $M$ $=.55, S D=.20 ; M=.51, S D=.19)$. No difference between the control and counterstereotypical conditions was found for automatic bias after White primes, $F(1,69)=.091$, $p=.764$. However, there was a significantly higher automatic bias in the control condition compared to the counter-stereotypical condition for Black primes, $F(1,69)=7.98, p=$ .006 .

\begin{tabular}{lcccc} 
& \multicolumn{4}{c}{ Prime } \\
\cline { 2 - 5 } & \multicolumn{2}{c}{ Black } & \multicolumn{2}{c}{ White } \\
\hline $\begin{array}{l}\text { Implementation } \\
\text { Intention Condition }\end{array}$ & $M$ & $S D$ & $M$ & $S D$ \\
\hline Counter-stereotypical & $.55_{\mathrm{a}}$ & .20 & $.51_{\mathrm{a}}$ & .19 \\
Control & $.68_{\mathrm{b}}$ & .17 & $.52_{\mathrm{a}}$ & .19
\end{tabular}

Table 2.1: Automatic Estimates by Prime and Implementation Intention. Estimates are probabilities (theoretical range from 0.0 to 1.0 ), such that values represent the probability of making a "gun" response when a tool has been presented (i.e., failure of control). Means with different subscripts differ at $p<.05$.

The elimination of stereotyping was due solely to a significant reduction in automatic bias or accessibility of the stereotype, as the estimates of controlled processing 
did not differ between conditions. A repeated measures ANOVA on the estimate of control, with race prime as a within-participant factor and implementation intention as a between-participant factor, found no Implementation intention x Race prime interaction, $F<1$, and no main effects (Table 2.2).

\begin{tabular}{lcccc} 
& \multicolumn{4}{c}{ Prime } \\
\cline { 2 - 5 } & \multicolumn{2}{c}{ Black } & \multicolumn{2}{c}{ White } \\
\hline $\begin{array}{l}\text { Implementation } \\
\text { Intention Condition }\end{array}$ & $M$ & $S D$ & $M$ & $S D$ \\
\hline Counter-stereotypical & $.57_{\mathrm{a}}$ & .20 & $.57_{\mathrm{a}}$ & .20 \\
Control & $.58_{\mathrm{a}}$ & .14 & $.58_{\mathrm{a}}$ & .18
\end{tabular}

Table 2.2: Cognitive Control Estimates by Prime and Implementation Intention. Estimates of control can range between a theoretical minimum and maximum of 0.0 and 1.0 with 1.0 representing perfect control in identifying guns and tools and 0.0 representing chance responding.

At this point, one might speculate that the reduction of automatic bias was a function of the counter-stereotypical implementation intentions inducing participants to simply slow down whenever they were presented with a Black face. This explanation, though, was not supported by the data. A repeated measures ANOVA on log transformed reaction times showed that participants in the counter-stereotypical condition did not slow down after Black faces $(M=333 \mathrm{~ms})$ relative to White faces $(M=334 \mathrm{~ms}), F<1$. Moreover, a repeated measures ANOVA with object (gun or tool) as a within participant factor and intention as a between participant factor was performed on reaction times for Black prime trials; this analysis showed that participants in the counter-stereotypical 
condition $(M=333 \mathrm{~ms})$ did not slow down after Black faces when compared to control participants $(M=342 \mathrm{~ms}), \mathrm{F}<1$. Nor was the Intention $\mathrm{x}$ Object interaction significant, $\mathrm{F}(1,68)=1.94, \mathrm{p}>.17$. Thus, participants in the counter-stereotypical intention condition did not appear to use any response bias strategy in which they took longer to respond after Black primes.

Another interesting question regarding effort involves the amount of practice that is needed to make implementation intentions efficient. Because the design of Experiment 1 included 3 blocks of trials, the effect of implementation intentions over time could be tested. A repeated measures ANOVA on errors with Block of trials as a withinparticipant factor and implementation intention as a between-participant factor showed that Block did not qualify the results. There was no four-way interaction, $F<1$. Followup analyses showed that the Implementation intention $\mathrm{x}$ Race prime $\mathrm{x}$ Object interaction was significant even in the first Block, $F(1,68)=4.89, p=.03$. Implementation intentions took effect very quickly, and remained effective throughout the task.

\section{Discussion}

This experiment provides strong support for the idea that conscious implementation intentions can reduce stereotyping by reducing automatic effects of the stereotype. The automatic bias results obtained from the process dissociation analysis in combination with the time-series and reaction time analyses demonstrate that the counterstereotypic implementation intentions reduced automatic bias, but not controlled processing (i.e., responding accurately as intended). Moreover, they reduced bias rapidly and without much effort or increased caution on the part of the participants. Thus, the 
reduction in automatic bias allowed participants' existing level of control to exert greater influence on their performance.

The finding that only automatic bias was reduced is particularly striking because many experiments using the weapon task have demonstrated that controlled processing can be increased (e.g., by taking longer), but none have shown that the automatic stereotyping bias can be reduced (Payne, 2001; Payne et al., 2002; Lambert et al., 2003). My research is among the first to support the idea that a specific strategy (i.e., an implementation intention) can be used to avoid problems with automatic activation of stereotypes when individuals are made aware of the possibility of bias. The counterstereotypical implementation intention appears to be an effective strategy for avoiding such accessibility effects and it appears to do so without impairing controlled thought, which could further exacerbate stereotyping especially if one is worried about appearing prejudiced (Monteith, Ashburn-Nardo, Voils, \& Czopp, 2002; Payne et al., 2002; Richeson \& Trawalter, 2005).

Although these results demonstrate that counter-stereotypical implementation intentions are an effective means for reducing automatic stereotyping, the scope of the effect is not yet known. On the one hand, implementation intentions might affect people's reactions only to the specific individuals about whom the intention is made. On the other hand, the effect of implementation intentions might be more general. The implementation intentions used here identified the targets at the level of an entire social group.

Participants' intentions focused on African Americans as a group, rather than the specific individuals used to represent that group. Therefore, the implementation intentions may extend to other African American individuals as well. From the perspective of practical 
applications, a broader effect would be much more useful. An anti-discrimination intervention that reduced discrimination only against a few specific individuals would have much less impact than an intervention that operated at the level of an entire social group. Because stereotyping itself operates at the group-level, a counter-stereotyping strategy that works at the group level would be ideal. To examine the scope and generality of this technique, I tested how well the effect generalized to a new set of faces in the next experiment. 


\section{CHAPTER 3}

\section{EXPERIMENT 2: GENERALIZATION OF THE EFFECT}

In Experiment 2, I again used the weapon identification task to restrict participants' ability to control responses. However, I added a manipulation in which previously unseen faces were presented to participants and I tested how well the counterstereotypical implementation intentions generalized (e.g., reduced stereotyping in response to the new faces). The first phase of the experiment was the same as in Experiment 1; but in the second phase, the faces used as priming stimuli were switched to a new set of Black and White individuals. If the effects I have observed are specific to the set of exemplars on which participants have practice using implementation intentions, then I can expect implementation intentions to reduce stereotyping for the original faces, but that stereotyping will re-appear for the new faces. In contrast, if the implementation intentions influence responses to the whole social category, then I can expect that they will reduce stereotyping for both original and new faces.

\section{Method}

Participants. One hundred twenty-five participants (63 female, 62 male) participated for course requirement. 
Design and Procedure. This experiment used the same manipulation of implementation intentions, the same weapon identification task, and the same instructions as Experiment 1, with two exceptions. First, the control intention was to think "quick" when participants saw a Black face; the counter-stereotypical intention remained the same (i.e., think "safe"). The control intention was altered from think "quickly" to think "quick" in the interest of keeping participants from construing the instruction to mean they were to think rapidly. Second, the 192 critical trials were divided into 4 blocks of 48 trials instead of 3 blocks of 64 trials each. Participants committed to their counterstereotypical or control implementation intention as was done in the previous experiment, and then preceded to complete 16 practice trials and 1 block of critical trials using the same four African American and four Caucasian faces as primes; faces in Block 1 were no longer novel because participants had formed their intentions with these faces and had seen them in the practice trials. Following this first critical block, participants completed a second and a third critical block with novel face primes that had not been used in the previous blocks (Appendix B).

Following these generalization blocks, participants completed a final block of trials that used the original faces from the first block of trials. The final block was included to control for the effects of practice. Other research has found that participants show decreases in stereotyping in weapon identification with practice (Plant, Peruche, \& Butz, 2005). If the generalization block was the final block, then any reduction in stereotyping could be explained by practice effects. Because practice effects would have a greater influence on the fourth block than on the second and third blocks, a design with a final non-generalization block allows the influence of practice to be distinguished from 
the generalization to new faces. The current experiment used a 2 (Implementation Intention: counter-stereotypical or control) x 2 (Race Prime: African American or Caucasian face) x 2 (Object: hand gun or tool) $\mathrm{x} 4$ (Block) design with prime, object, and block as within-participant factors.

\section{Results}

The first analysis was conducted to establish whether the findings from Experiment 1 were replicated in Experiment 2. In this analysis, I tested the influence of implementation intentions on performance, ignoring the factor of novel versus practiced faces. Error rates were analyzed using a 2 (Implementation intention: counterstereotypical or control) x 2 (Race prime: African American or Caucasian) x 2 (Object: gun or tool) repeated measures ANOVA, with race prime and object as repeated measures. I observed the expected Race prime x Object stereotyping interaction in which participants falsely identified a tool as a gun more often after being primed with a Black compared to a White face, and falsely identified a gun as a tool more often after a White face, $F(1,123)=35.41, \mathrm{p}<.001$.

Most importantly, as in the previous experiment, this interaction was qualified by the predicted three-way Implementation intention $\mathrm{x}$ Race prime $\mathrm{x}$ Object interaction, $F(1,123)=12.16, p=.001$. Participants in the control condition showed significant stereotyping, as indicated by the Race prime $\mathrm{x}$ Object interaction, $F(1,61)=38.97, p<$ .001. In contrast, those in the counter-stereotypical implementation intention condition showed much less stereotyping, and the Race prime x Object interaction was only marginally significant, $F(1,62)=3.52, p=.07$ (Figure 3.1 on page 33 ). This analysis 
showed that the significant reduction in stereotyping observed in Experiment 1 replicated even when previously unseen faces were included as primes; thus, the effect of the counter-stereotypical implementation intention was not limited to the faces participants had seen when creating their intention. 

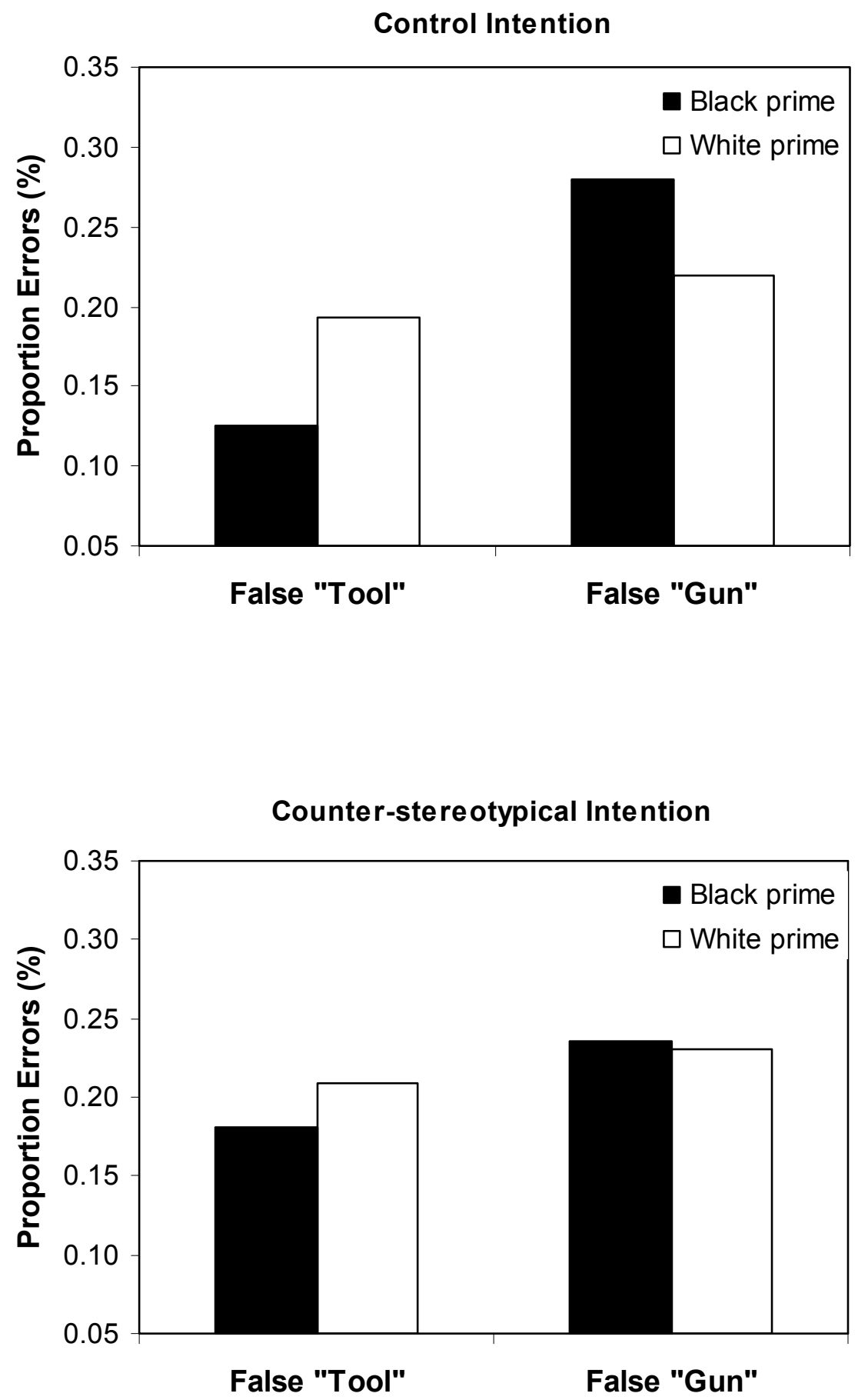

Figure 3.1: Proportion of errors by type of Object error (false "gun" versus false "tool" response), Race prime (White versus Black), and Implementation intention condition (counter-stereotypical versus control). 
The Intention $\mathrm{x}$ Race prime $\mathrm{x}$ Object analysis was repeated next with the Block variable included to test whether the effectiveness of the implementation intentions differed across blocks. This Block variable did not qualify the results, as evidenced by the lack of a four-way interaction, $F<1$. To more clearly graph the effect of different Blocks on performance, the Race prime $\mathrm{x}$ Object interaction was converted into a single performance bias score. The performance bias score was computed as the proportion of stereotype-congruent errors (false "gun" on Black prime trials + false "tool" responses on White prime trials) minus the proportion of stereotype-incongruent errors (false "tool" responses on Black prime trials + false "gun" on White prime trials). Higher values on this score represent greater stereotyping. As shown in Figure 3.2 on page 35, the effect of implementation intentions was uniform across blocks and there was no interaction involving the Block variable. Importantly, this result indicates that the counterstereotypical intention generalized to new faces because the new faces inserted into blocks 2 and 3 did not alter responses. 


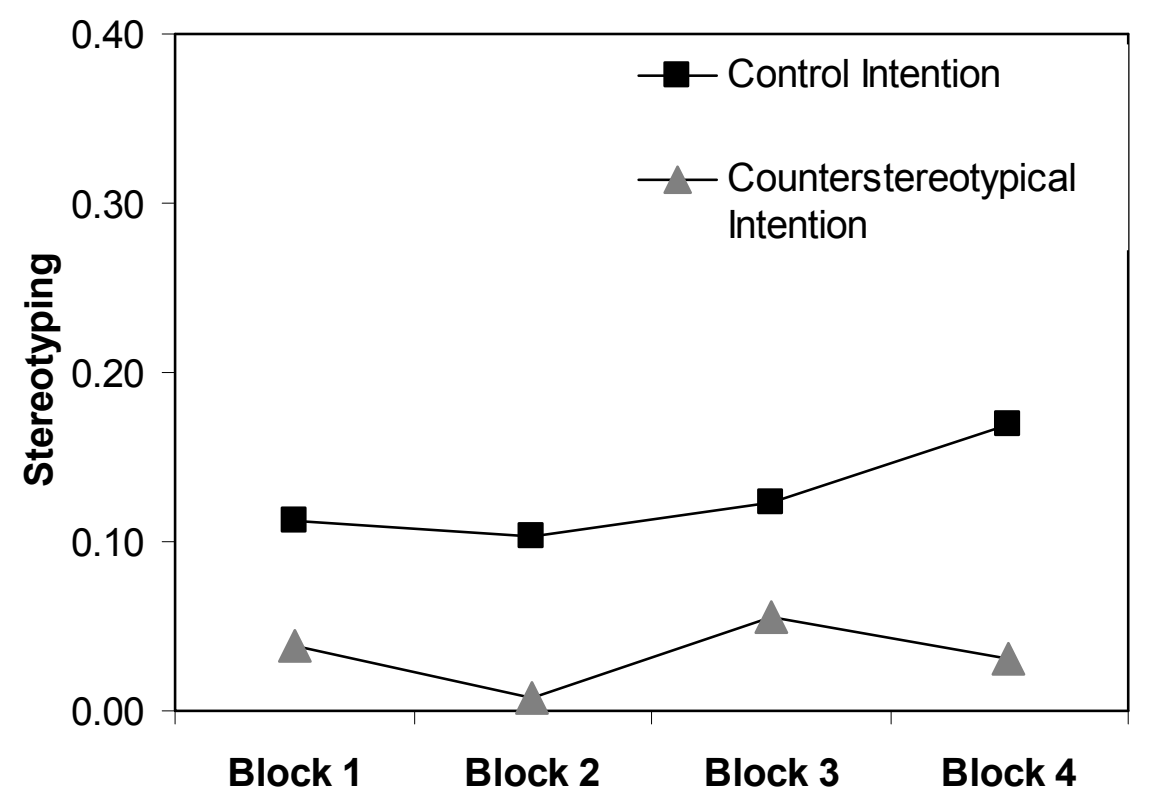

Figure 3.2: Stereotypical performance bias as a function of Block and Implementation intention condition (counter-stereotypical versus control).

A final analysis on errors was conducted to test whether the reduction in stereotyping was once again due to responses becoming less stereotypical after Black primes, as was the case in Experiment 1. For White prime trials, there was a nonsignificant Intention x Object error interaction, $F<1$. Again, this equivalence of false "gun" and false "tool" errors between the control and counter-stereotypical conditions indicated that the intentions did not alter responses to White primes. For Black prime trials, there was a significant Intention $\mathrm{x}$ Object error interaction, $F(1,123)=13.84, p<$ .001. Again, participants in the counter-stereotypical intention condition showed fewer stereotypical errors (e.g., False "gun" errors) on Black prime trials. 


\section{Automatic and Controlled Estimates}

Automatic and controlled estimates were computed so that higher numbers represented a greater bias toward responding 'gun." Stereotyping is observed when this "gun" bias is higher after a Black prime than after a White prime. A repeated measures ANOVA on automatic bias with race prime as a within-participant factor and implementation intention as a between-participant factor revealed a significant Implementation intention $\mathrm{x}$ Race prime interaction, $F(1,123)=9.29, p=.003$. Simple effects tests showed that automatic stereotype bias (i.e., higher "gun" bias after Black primes than after White primes) was significant in the control intention condition $(M=$ $.70, M=.51)$ and in the counter-stereotypical condition $(M=.58, M=.51$; Table 3.1$)$. However, the automatic bias after Black primes was significantly smaller in the implementation intention condition $(M=.58 ; S D=.19)$ when compared to the control condition $(M=.70 ; S D=.15)$. No difference between the control and counterstereotypical conditions was found for automatic bias after White prime, $F<1$.

\begin{tabular}{lcccc} 
& \multicolumn{4}{c}{ Prime } \\
\cline { 2 - 5 } & \multicolumn{2}{c}{ Black } & \multicolumn{2}{c}{ White } \\
\hline $\begin{array}{l}\text { Implementation } \\
\text { Intention Condition }\end{array}$ & $M$ & $S D$ & $M$ & $S D$ \\
\hline Counter-stereotypical & $.58_{\mathrm{c}}$ & .19 & $.51_{\mathrm{a}}$ & .17 \\
Control & $.70_{\mathrm{b}}$ & .15 & $.51_{\mathrm{a}}$ & .17
\end{tabular}

Table 3.1. Automatic Estimates by Prime and Implementation Intention. Estimates are probabilities (theoretical range from 0.0 to 1.0), such that values represent the probability of making a "gun" response when a tool is presented (i.e., failure of control) control fails. Means with different subscripts differ at $p<.05$. 
The effect of implementation intentions on automatic bias was not qualified by Block, confirming that the reduction in automatic bias was uniform across novel and practiced exemplars, $F(1,121)=1.26, p=.291$. As was expected, no differences between implementation intention and control conditions were observed for the estimate of controlled responding, $F<1$, or on self-reported amount of effort on the task, $F<1$. Furthermore, A repeated measures ANOVA on log transformed reaction times showed that participants in the counter-stereotypical condition did not slow down after Black faces $(M=342 \mathrm{~ms})$ relative to White faces $(M=343 \mathrm{~ms}), F<1$. And a repeated measures ANOVA with object (gun or tool) as a within participant factor and intention as a between participant factor was performed on reaction times for Black prime trials; this analysis demonstrated that participants in the counter-stereotypical condition $(M=342$ ms) did not slow down after just Black faces when compared to control participants ( $M=$ $331 \mathrm{~ms}), F<1$. The Intention $\mathrm{x}$ Object interaction also was not significant, $F<1$. These findings regarding process estimates and reaction time analyses were consistent with results of the previous experiment. Counter-stereotypical implementation intentions reduced automatic stereotyping and did so quickly and efficiently.

\section{Discussion}

Experiment 2 replicated the finding that a conscious, counter-stereotypical implementation intention reduced automatic bias without affecting controlled responding. Importantly, this effect was observed for previously unseen faces, thus, it was operating at the level of the whole social category, which is important because stereotyping operates at this level. Further, Experiment 2 found that having practice with faces did not 
improve performance for participants in the control condition. Participants in this condition showed stereotyping in the first block of trials, and equivalent or higher levels of stereotyping in the remaining three blocks; thus, stereotyping did not disappear with practice in completing the task. Importantly, this persistent stereotyping effect was countered by the conscious, counter-stereotypical intentions. Participants in this condition showed no stereotyping in the first block and this reduction in stereotyping was maintained throughout the task. 


\section{CHAPTER 4}

\section{EXPERIMENT 3: ALTERING VISUAL ATTENTION}

Stereotypes are chronic associations or beliefs that may be activated when participants categorize individuals according to a social category. The influence of racial stereotypes was readily apparent in the control conditions of the previous two experiments using the weapon identification paradigm. Participants were warned about the potential influence of race on their judgments. This warning subtly influenced them to categorize face primes by their race, which activated relevant stereotypes for many participants. Once activated, these stereotypes and associations caused participants to misidentify objects in a stereotypical way (i.e., calling a tool a gun after a Black prime, and a gun a tool after a White prime). Within this weapon identification task, having stereotypical thoughts of crime, danger, or weapons come to mind after seeing a Black face prompted people to respond "gun", and thus, make stereotypical errors, unless they could exert controlled thinking and respond accurately as instructed.

Stereotypical thoughts may also influence the focus of an individual's attention after seeing a member of a social group. In situations in which weapons and non-weapons are present, stereotypical thoughts of crime, danger, and weapons may come to mind after seeing an African American and this may cause attention to shift to weapons- $\mathrm{a}$ stereotypical attentional bias. 
Consider the processes that may create this stereotypical attentional bias. A person may see someone holding a few objects, and then try to determine whether the situation and the objects are threatening. Categorizing this person on the basis of race can cause the thoughts and feelings associated with the social category to be activated, which may lead to stereotypical responses; in this case, such responses may entail shifting attention to any features in the visual field that are consistent with the activated stereotypes. Thus, weapons may enjoy an attentional advantage after a person sees a young Black man. However, the perceiver is also focusing on the objects and trying to identify them accurately. Thus, one stream of information - stereotypical thoughts and feelings - could lead to attentional bias to weapons or weapon-like qualities of safe objects (e.g., a flashlight being the same size as a gun) when objects compete for attention. The other stream of information - scrutiny of the available visual features would lead to more equivalent levels of attention to the various objects, and perhaps disengagement from the weapons in the interest of a more comprehensive search. Providing participants with a counter-stereotypical implementation intention may reduce attentional bias to weapons, and facilitate disengagement from weapons because the implementation intention lessens stereotypical thoughts.

Research in the areas of vision and social cognition has supported the idea that expectations or primes can influence visual attention by directing it to features of the stimuli that are relevant to the perceiver's expectations (Connor, Egeth, \& Yantis, 2004; Macrae et al., 1997; Wolfe, Butcher, Lee, \& Hyle, 2003). This attentional bias can be created intentionally by explicit goals or unintentionally by salient stimuli or expectations that are either activated subliminally without one's awareness or without one's 
knowledge of the carry-over effects (Eberhardt, Goff, Purdie, \& Davies, 2004; GrillSpector, Kushnir, Hendler, \& Malach, 2000; Kristjansson, Wang, \& Nakayama, 2002; Serences et al., 2005). For example, implicit priming has been shown to speed visual searches in a conjunction search paradigm. People are faster to find a red, vertical target if the previous target was a red, vertical target than if it had been a green horizontal target. Another line of research found that social category primes of Black and White faces induced stereotypical attentional bias (Eberhardt et al., 2004). In this experiment, participants who were subliminally primed with Black faces were faster to identify crimerelated images than those participants primed with White faces. These participants attended to features of later-presented stimuli that were connected to participants' expectations or stereotypes about the social category. Based upon this research it is likely that there will be attentional bias to weapons after seeing an African American.

A major technique for measuring where attention is focused at a given point-intime (i.e., attentional bias) is the probe detection task (Bradley, Mogg, Falla, \& Hamilton, 1998; MacLeod, Mathews, \& Tata, 1986; Mogg \& Bradley, 1999); this technique was developed to measure clinically anxious participants' attentional bias to threat information by assessing their attention to threat-relevant stimuli. Although there are a number of variations of this task, the primary procedure includes presenting participants with words or pictures that participants find threatening or non-threatening; for example, spider-phobic participants would be presented with spiders and other insects. Both a threatening and a non-threatening picture or word are presented on a screen simultaneously for a period of 500 to $750 \mathrm{~ms}$. After that time, a small dot appears in the location in which either the threatening or non-threatening object had been. Attentional 
bias is observed when spider-phobic participants are faster to identify a dot in the location of a threatening object when compared to a non-threatening object. In effect, the latencies provide an indication - a virtual snapshot - of where visual attention is fixated at the point-in-time when the dot is presented. The literature now supports this view that the probe detection method reveals where attention was at the moment of the dot's presentation and not whether an object attracted attention first or immediately (Bradley, Mogg, \& Millar, 2000; Mogg \& Bradley, 1999; Mansell, Clark, Ehlers, \& Chen, 1999). The probe detection task has become a standard for measuring attentional bias of individuals diagnosed with clinical anxiety and social phobia (Eysenck, 1992; GilboaSchechtman, Foa, \& Amir, 1999; MacLeod et al., 1986; Mansell et al., 1999; Mathews \& MacLeod, 1985) and depression (Gotlib, McLachlan, \& Katz, 1988). Importantly, it has also been used to assess attentional bias between the stereotype of criminal and the African American social category (Eberhardt et al., 2004). In one experiment (Experiment 2), participants were subliminally primed with crime images (e.g., guns, police badges, fingerprints, etc.), and then were shown a fixation dot on the center of the screen for 2 to 6 seconds. After the dot, participants saw a Black and a White face for 450 ms with each located on the outer edge of their peripheral vision (i.e., six degrees to the right or left of center). After the faces disappeared from the screen, a small dot appeared where one of the faces had been; this dot location was randomly determined. Reaction times were recorded from the time the dot was presented until the participant responded. The observed results showed that participants were faster to identify the dot where the White face had been after a no-crime prime, and this effect was reversed for the crime prime; participants were faster to respond when the dot was behind the Black face after 
the crime prime. These results indicated that the concept of crime is linked to the African American social category, strongly enough that activation of the crime concept caused participants to show attentional bias for Black faces. Overall, this study indicates that the probe detection task is a valid measure of stereotypical attentional bias.

In my third experiment, I was interested in testing whether a counter-stereotypical implementation intention (think "safe") would reduce stereotypical attentional bias to weapons, especially after Black faces. In this experiment, participants would see a Black or White face for $200 \mathrm{~ms}$, and then see a gun and a phone, which would disappear after $300 \mathrm{~ms}$. A dot then would appear where one of the objects had been. Research has demonstrated that in situations in which guns are present there is a general tendency to focus attention on weapons, possibly because weapons are potential threats to individuals (Pickel, Ross, \& Truelove, 2006; Shaw \& Skolnick, 1999; Steblay, 1992; Tooley, Brigham, Maass, \& Bothwell, 1987). I would expect this weapon bias to be exacerbated when people are primed with social categories that are stereotypically associated with weapons. Therefore, the Black prime should elicit stereotypical thoughts, and cause participants to pay more attention to guns than phones. I would not expect this stereotypical attentional bias to occur in the counter-stereotypical condition. If counterstereotypical implementation intentions reduce stereotypical thoughts, then participants should show less stereotypical attentional bias to weapons; for these participants, attention would be kept off of the weapon. 


\section{Method}

Participants. One hundred and three participants (52 female, 51 male) from introductory psychology courses participated for course credit. One participant was removed because of incomplete data that created empty cells for the reaction time analyses.

Design and Procedure. The experiment used a 2 (Implementation Intention: counter-stereotypical or control) x 2 (Race Prime: African American or Caucasian face) x 2 (Dot Position: gun or phone location) design with race prime and dot position as within-participant factors. After being seated at separate computers, participants were informed that the experiment involved attentional vigilance. They were told that they would see a face followed by two objects, a gun and a phone, and that when the objects disappeared from the screen, a dot would appear where one of the objects had been. Their job was to identify whether the dot had appeared on the left or the right of the screen as quickly and accurately as they could. As has been done in previous research, participants were told that the task was intended to examine whether seeing the faces would affect peoples' ability to respond quickly and accurately (Eberhardt et al., 2004). To become acquainted with the task, participants completed 16 practice trials before the critical trials began. Participants were not given any information about the influence of race on seeing guns and phones until after the implementation intention manipulation.

The probe detection task exposed participants to pairs of pictures. The first picture (the prime) included black and white photographs $(5.3 \mathrm{~cm} \mathrm{x} 4 \mathrm{~cm})$ of four African American male and four Caucasian male faces (Appendix C). The second picture included a hand gun $(5.3 \mathrm{~cm} \times 3.3 \mathrm{~cm})$ and a cell phone $(5.3 \mathrm{~cm} \times 3.3 \mathrm{~cm})$ with each 
positioned on the left or right side of the screen; there were four gun pictures and four phone pictures paired equally and counterbalanced by left and right presentation to create thirty-two images (Appendix D). The face prime remained on the screen for $200 \mathrm{~ms}$ and it then was replaced by the gun and phone picture for $300 \mathrm{~ms}$; the gun and phone each appeared $5.5^{\circ}$ to the left and ride side of the screen an equivalent number of times. After the gun and the phone were presented, a small grey dot appeared in the location of either the gun or phone; dot location was randomized throughout the critical trials. For each trial, the prime appeared $500 \mathrm{~ms}$ after the previous response.

Following the basic instructions and practice trials, participants received the implementation intention manipulation. As was done in the previous experiments, all participants were told that the race of the face impacts the way that people respond to the objects (guns and phones). They were not told explicitly that the race of the faces would cause them to attend to stereotype-consistent objects; nevertheless, the race of the faces was made salient, which would encourage participants to categorize the faces by race. They also were told that they may be able to change their reactions and were asked to choose the type of face to which they would respond.

Participants in the counter-stereotypical implementation intention condition were told, "In order to firmly commit yourself to responding to the Black face by thinking 'safe', please say to yourself silently, I definitely want to respond to the Black face by thinking, 'safe'." Participants in the control condition were told, "In order to firmly commit yourself to responding to the Black face by thinking 'quick', please say to yourself silently, I definitely want to respond to the Black face by thinking, 'quick'." 
Following the manipulation, participants completed 192 critical trials divided into three blocks of 64 trials each. Gun-phone pairs and dot position were presented in random order and were counterbalanced fully.

\section{Results}

Data Reduction: Following precedence of past research, I removed reaction times for trials in which an error was made. This resulted in the loss of $5.1 \%$ of the data, which is an acceptable level and is consistent with past research using this paradigm (Bradley, et al., 1998; Eberhardt et al., MacLeod et al., 1986; Mogg \& Bradley, 1999). To reduce problems of skewness created by very short and very long reaction times, those reaction times of less than $250 \mathrm{~ms}$ were recoded to $250 \mathrm{~ms}$, and those greater than $3,000 \mathrm{~ms}$ were recoded to $3,000 \mathrm{~ms}$; this recoding affected only $3.8 \%$ of the data. All reaction times were then $\log$ transformed.

A 2 (Implementation intention: counter-stereotypical or control) x 2 (Race prime: African American or Caucasian) x 2 (Dot position: gun or phone location) x 2 (Side: dot on left or right) repeated measures ANOVA, with race prime, dot position, and side as repeated measures, was performed on the reaction times. A significant main effect of race prime emerged in which all participants responded faster after Black primes $(M=378$ $\mathrm{ms}$ ) than after White primes $(M=382 \mathrm{~ms}), F(1,100) 4.17, p=.044$. Significant main effects also emerged for presentation side, $F(1,100)=7.14, p=.009^{2}$, and dot position (i.e., gun or phone location), $F(1,100)=9.02, p=.003$. Participants responded faster to dots on the left side of the screen $(M=377 \mathrm{~ms})$ than the right side $(M=383 \mathrm{~ms})$, and to dots in the location of a gun $(M=375 \mathrm{~ms})$ than the location of the phone $(M=385 \mathrm{~ms})$. 
The previous main effects were qualified by the expected Implementation intention $\mathrm{x}$ Race prime $\mathrm{x}$ Dot position interaction, $F(1,100)=4.82, p=.031$. In the control intention condition, a significant Race prime x Dot position interaction emerged, $F(1,48)=4.48, p=.04$ (Figure 4.1, page 48). Relative to their latencies on the White prime trials, participants responded faster to a dot in the location of the gun than in the location of the phone after Black primes; this pattern of responding represents stereotyping. In contrast, the Race $\mathrm{x}$ Dot position interaction was not significant for participants in the counter-stereotypical intention condition, $F(1,52)<1, p=.440$. These participants did not respond faster to a dot in the location of the gun than the phone after Black primes compared to White primes.

Furthermore, when comparing the control and counter-stereotypical participants' responses after Black primes, there was a marginally significant Intention x Dot Position interaction, $F(1,100)=3.02, p=.086$; participants in the counter-stereotypical condition showed less stereotypical attentional bias after Black primes than did participants in the control condition, which is consistent with the results of Experiments 1 and 2. 

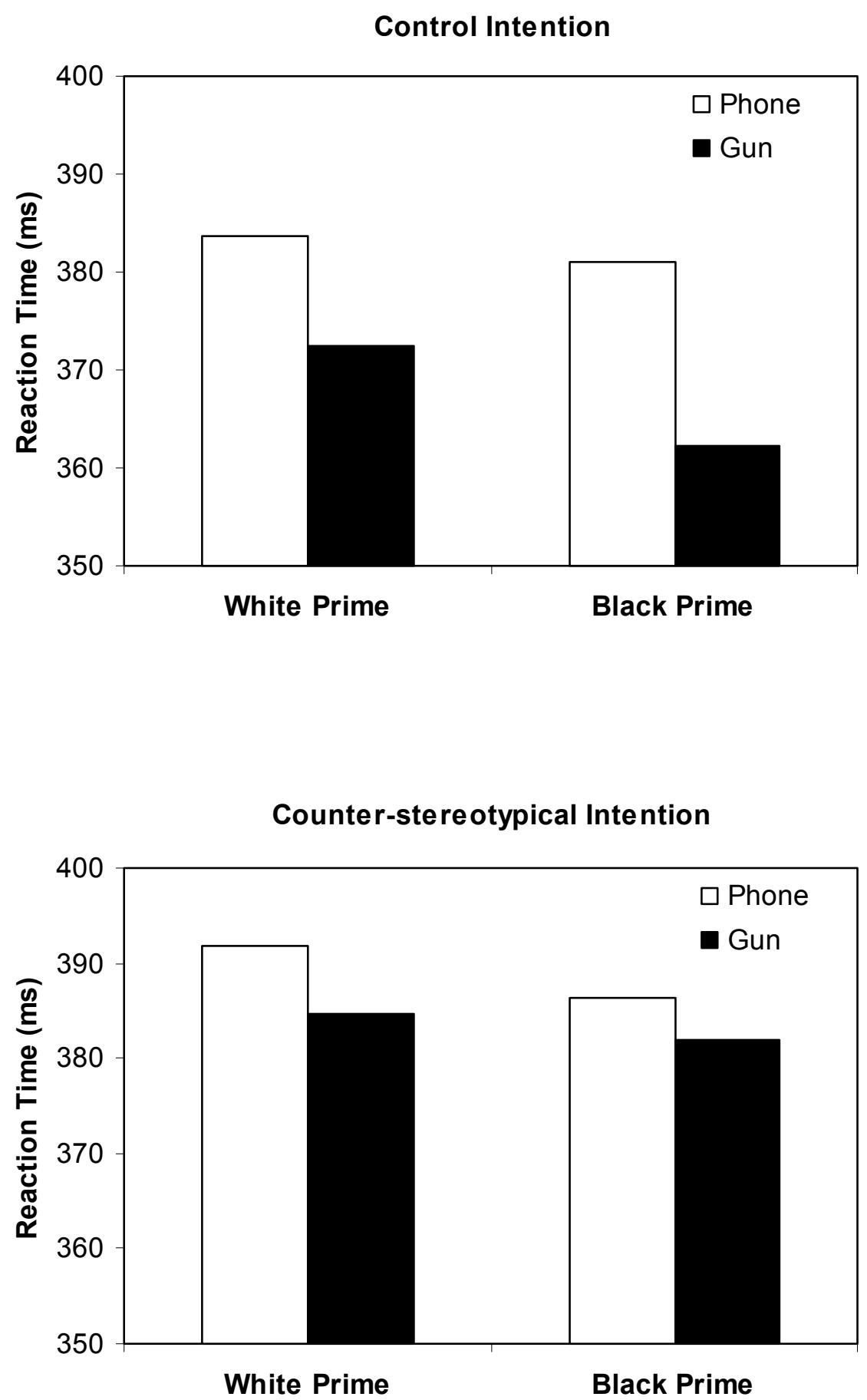

Figure 4.1: Reaction time (re-transformed to milliseconds from log transformed means) as a function of the Race prime (Black or White) and Dot position (after a gun or a phone), and Implementation intention condition (counter-stereotypical versus control). 


\section{Discussion}

In this experiment, participants in the control intention condition exhibited faster reactions to probes in the gun position than the phone position, and this stereotypecongruent attentional bias was stronger after Black primes than after White primes; thus, stereotypical associations seem to have been activated and to have influenced visual attention. This stereotypical attentional bias was significantly reduced in the counterstereotypical intention condition; these participants were not faster to identify probes in the gun position than the phone position after Black primes or after White primes. Thus, it appears that the influence of stereotypical associations was diminished by the counterstereotypical implementation intention.

It is interesting to note that a weapon bias, in which participants responded faster to a dot in the gun location than the phone location, was observed in the control condition for the White prime trials. This weapon bias may have occurred because the stereotypical association between phone and the Caucasian social category was not strong; thus, it was not able to override the general attentional bias to weapons, which has been observed in this and other psychological research (Pickel et al., 2006; Shaw \& Skolnick, 1999; Steblay, 1992). Such a weapons bias may occur for a few reasons. First, weapons may be the more hedonically significant of the two stimuli, possibly because they indicate a potential threat (Roskos-Ewoldsen \& Fazio, 1992). Second, weapons may be so strongly associated with an interracial context in which a weapon may appear that the weapons draw attention when presented with more mundane objects (Eberhardt et al., 2004). Future research will need to be conducted to identify the most likely cause of this weapon bias. 
An aspect of the general manipulation of implementation intentions warrants elaboration at this point because it is different from other research that investigates the influence of stereotypes on attentional bias. Past research has shown that divided attention, due to a dual-task paradigm, increases the extraction of the conceptual meaning of stereotype-congruent information, but divided attention also can increase participants' attention to stereotype-incongruent information (Sherman, Conrey, \& Groom, 2004; Sherman, Lee, Bessenoff, \& Frost, 1998). This past research is different from my research on attentional bias in two important ways. First, the task I use to measure attentional bias does not present stereotype-incongruent or unexpected information; therefore, the non-stereotypical information presented would not seem more unexpected than the stereotypical information and participants would not be more likely to attend to it because of its unexpectedness. Second, the general task and task instructions encourage hurried and fast responding. It is likely that people in a hurried situation respond differently than those in a divided attention situation. People who are responding quickly may be influenced more by stereotypical thoughts that come to mind quickly, which may cause them to focus on objects that are connected to those stereotypes.

Past research has found that having people respond quickly increases the accessibility of stereotypes and produces stereotypical errors, and it is likely that such a process also encourages people to focus attention on stereotype-congruent objects (Payne, 2001; Payne et al., 2002). In the current dot probe experiment, participants showed such a stereotype-congruent attentional bias in situations in which they were responding quickly (average reaction time was $400 \mathrm{~ms}$ ). The counter-stereotypical implementation intention, however, eliminated this stereotypical attentional bias. Given 
that this effect of counter-stereotypical intentions occurred when the gun and phone had been presented for only $300 \mathrm{~ms}$, it seems like it was largely automatic. If this effect were due to controlled thinking, such thinking would have had to have been, at minimum, extraordinarily efficient. While this finding is very intriguing, a more thorough examination of this effect is needed because the experiment involved a "snapshot" at only a single point-in-time. Thus, the timing parameters were varied in Experiment 4 to determine the time course of this effect within the probe detection task. 


\section{CHAPTER 5}

\section{EXPERIMENT 4}

In the previous experiment, I used a probe detection task, but measured attentional bias at only one time point. In order to examine more thoroughly the effect of implementation intentions on stereotypical attentional bias, I conducted an experiment in which the gun and phone pictures remained on the screen for longer and shorter periods of time. Taking a "later" snapshot at $550 \mathrm{~ms}$ allowed for assessing the influence of implementation intentions on disengaging and keeping attention away from weapons. Taking a snapshot at $250 \mathrm{~ms}$ provided a comparison point "early" in the process.

In this experiment, I set the upper presentation condition to $550 \mathrm{~ms}$ to investigate whether counter-stereotypical implementation intentions shifted and held attention away from stereotypical objects. I set the lower presentation condition to $250 \mathrm{~ms}$. This condition was slightly faster than the previous $300 \mathrm{~ms}$ experiment in which participants in the control condition showed stereotypical attentional bias. I was concerned about setting the presentation time much faster than $250 \mathrm{~ms}$ because pilot testing revealed no stereotypical attentional bias at $100 \mathrm{~ms}$. Thus, it appears that some minimum threshold needs to be achieved for the attentional bias to emerge. In any case, including two presentation times permited examination of how disengagement of attention unfolded over time and how counter-stereotypical intentions impacted this process. 


\section{Method}

Participants. One hundred and eighty-four participants (106 female, 78 male) from introductory psychology courses participated for course credit.

Design and Procedure. This experiment used the same manipulation of implementation intentions, the same probe detection task, and the same instructions as Experiment 3, with one exception. In this experiment, presentation time of the gun and phone pictures was varied between conditions (250 ms and $550 \mathrm{~ms})$. The experiment used a 2 (Implementation Intention: counter-stereotypical or control) x 2 (Presentation Time: $250 \mathrm{~ms}$ or $550 \mathrm{~ms}$ ) x 2 (Race Prime: African American or Caucasian face) x 2 (Dot Position: gun or phone location) design with race prime and dot position as withinparticipant factors.

Once again, participants were informed that the experiment involved attentional vigilance, and that they would be trying to identify whether the dot had appeared on the left or the right of the screen as quickly and accurately as they could. They were given 16 practice trials before the critical trials began. After the practice trials, participants were told about the potential influence of race and given either the control or the counterstereotypical implementation intention.

\section{Results}

Data Reduction: Reaction times for trials in which an error was made were removed, which resulted in a loss of $5.4 \%$ of the data. Again, recoding was conducted to reduce skewness from very short and very long reaction times. Those reaction times of 
less than $250 \mathrm{~ms}$ were recoded to $250 \mathrm{~ms}$, and those greater than $3,000 \mathrm{~ms}$ were recoded to $3,000 \mathrm{~ms}$, which affected $3.3 \%$ of the data. All reaction times were then $\log$ transformed.

I conducted a 2 (Intention: counter-stereotypical or control) x 2 (Presentation time: 250 or $550 \mathrm{~ms}$ ) $\mathrm{2}$ (Race prime: African American or Caucasian) x 2 (Dot position: gun or phone location) x 2 (Side: dot on left or right) repeated measures ANOVA on reaction times, with race prime, dot position, and side as repeated measures. A significant Race prime $\mathrm{x}$ Implementation intention was found, $F(1,180)=5.04, p=$ .026; participants in the control condition were faster in responding after a Black prime ( $M=372 \mathrm{~ms})$ than after a White prime $(M=381 \mathrm{~ms})$ while participants in the counterstereotypical condition were not $(M=381 \mathrm{~ms}, M=383 \mathrm{~ms})$. A significant Dot position x Time interaction was also found, $F(1,180)=9.85, p=.002$. Participants in the $250 \mathrm{~ms}$ condition responded faster to a dot in the gun location $(M=375 \mathrm{~ms})$ than the phone location $(M=385 \mathrm{~ms})$; no such difference was observed for participants in the $550 \mathrm{~ms}$ condition $(M=377 \mathrm{~ms} ; M=379 \mathrm{~ms})$.

The Implementation intention $\mathrm{x}$ Time $\mathrm{x}$ Race prime $\mathrm{x}$ Dot position interaction, which could have revealed differential patterns across time, was not significant, $F(1,180)$ $=1.20, p=.275$. Even though this four-way interaction was not significant, I was very interested in investigating the effect of implementation intentions at the two different time intervals of $250 \mathrm{~ms}$ and $550 \mathrm{~ms}$.

For the 250 ms conditions, a 2 (Implementation intention: counter-stereotypical or control) x 2 (Race prime: African American or Caucasian) x 2 (Dot position: gun or phone location) x 2 (Side: dot on left or right side) repeated measures ANOVA was 
performed on reactions times, with race prime, dot position, and side as repeated measures. A significant main effect of dot position (i.e., gun or phone location) was observed, $F(1,88)=20.15, p<.001$; all participants were faster to identify a dot in the gun location $(M=375 \mathrm{~ms})$ than in the phone location $(M=385 \mathrm{~ms})$. This main effect was moderated by a significant Intention $\mathrm{x}$ Race prime interaction, $F(1,88)=3.85, p=.053$; participants in the counter-stereotypical condition were slightly slower in responding after a Black prime $(M=385 \mathrm{~ms})$ than were participants in the control condition $(M=$ $372 \mathrm{~ms})$.

The expected Intention $\mathrm{x}$ Race prime $\mathrm{x}$ Dot position interaction also was not significant, $F<1$, indicating that the intention manipulation did not produce differential attention to guns versus phones as a function of the race prime. Further analyses indicated that the expected Race prime $\mathrm{x}$ Dot position interaction was not observed in the control condition, $F<1$ (Figure 5.1, page 57). Instead, only a main effect of dot position emerged, $F(1,45)=18.01, p<.001$. Across Black and White prime trials, participants responded significantly faster to a dot in the location of the gun $(M=369 \mathrm{~ms})$ than in the location of the phone $(M=383 \mathrm{~ms})$. Thus, there appears to have been attentional bias to guns that was not moderated by the race prime. This is interesting because it does not replicate the significant Race $\mathrm{x}$ Dot position interaction observed in the control condition of Experiment 3 in which participants were given slightly more time to view the pictures of guns and phones.

In the counter-stereotypical intention condition, the Race prime $\mathrm{x}$ Dot position interaction also was not observed, $F<1$. Just as in the control condition, participants displayed an overall attentional bias in favor of guns. That is, collapsed across the Black 
and White prime trials, participants responded significantly faster to a dot in the location of the gun $(M=381 \mathrm{~ms})$ than in the location of the phone $(M=388 \mathrm{~ms}), F(1,43)=4.51$, $p=.04$. No other higher order interactions were significant in either the control or the counter-stereotypical conditions. 


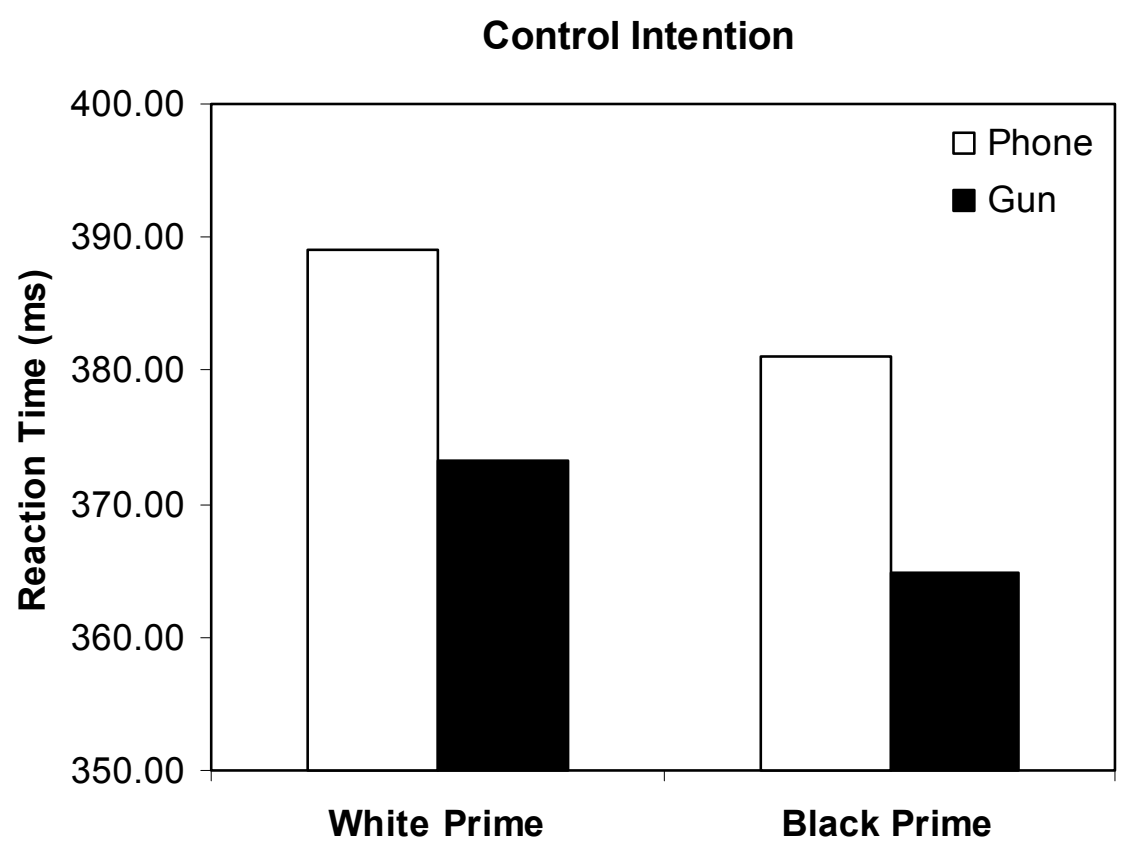

Counter-stereotypical Intention

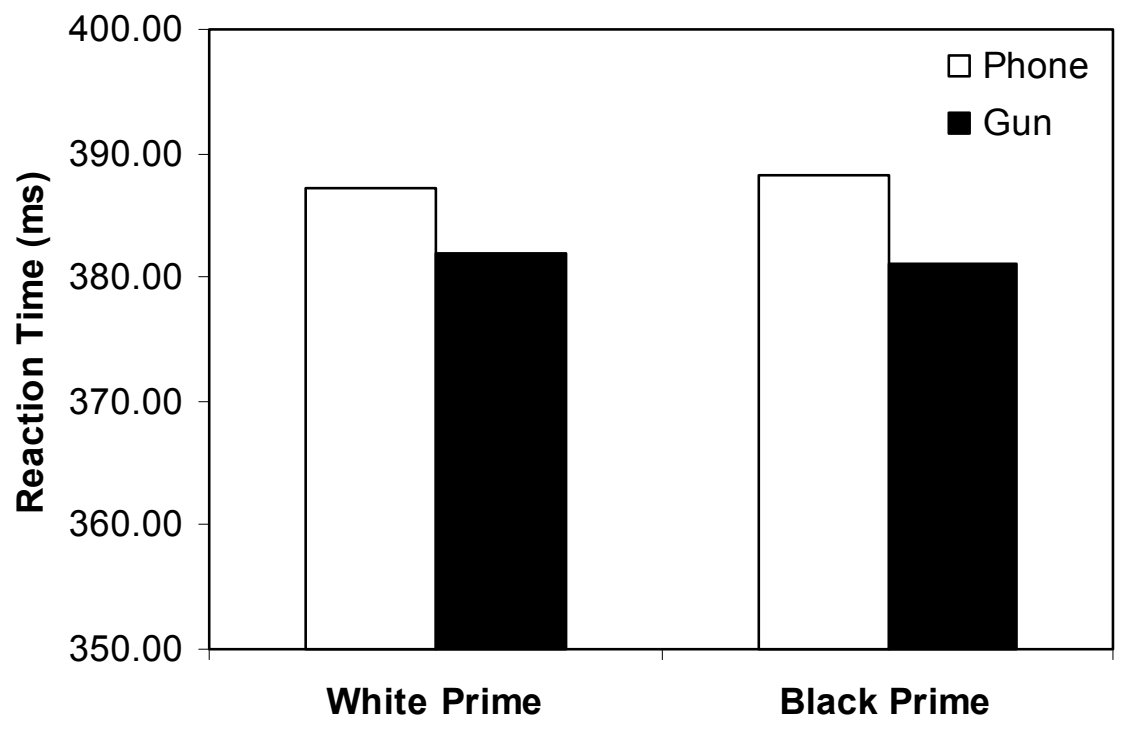

Figure 5.1: Reaction time (re-transformed to milliseconds from log transformed means) as a function of the Race prime, Dot position (after gun or phone), Implementation intention condition (counter-stereotypical versus control), and the $250 \mathrm{~ms}$ condition. 
A 2 (Implementation intention: counter-stereotypical or control) x 2 (Race prime: African American or Caucasian) x 2 (Dot position: gun or phone location) x 2 (Side: dot on left or right) repeated measures ANOVA, with race prime, dot position, and side as repeated measures, also was performed on the reaction times within the $550 \mathrm{~ms}$ condition. In contrast to what had been observed for the $250 \mathrm{~ms}$ condition, the expected Implementation intention $\mathrm{x}$ Race prime $\mathrm{x}$ Dot position interaction was significant, $F(1,92)=4.20, p=.043$ (Figure 5.2, page 59).

For participants in the control intention condition, the expected Race prime $\mathrm{x}$ Dot position interaction was significant, $F(1,45)=6.71, p=.013$. After Black primes, participants responded more quickly to the dot in the gun location than in the phone location; there was no such difference for White prime trials. This pattern of responses indicates stereotyping. For participants in the counter-stereotypical intention condition, the Race prime $\mathrm{x}$ Dot position interaction was non-significant, $F<1$. Participants in this condition were now slightly slower in responding to a dot in the gun location than the in the phone location after Black primes; thus, it appears that these participants were not responding stereotypically. Furthermore, when comparing the control and counterstereotypical participants' reactions to Black primes, I observed a significant Intention $\mathrm{x}$ Dot position interaction, $F(1,92)=4.12, \mathrm{p}=.045$. This significant interaction indicated that the counter-stereotypical implementation intention reduced stereotypical attentional bias after Black primes. 


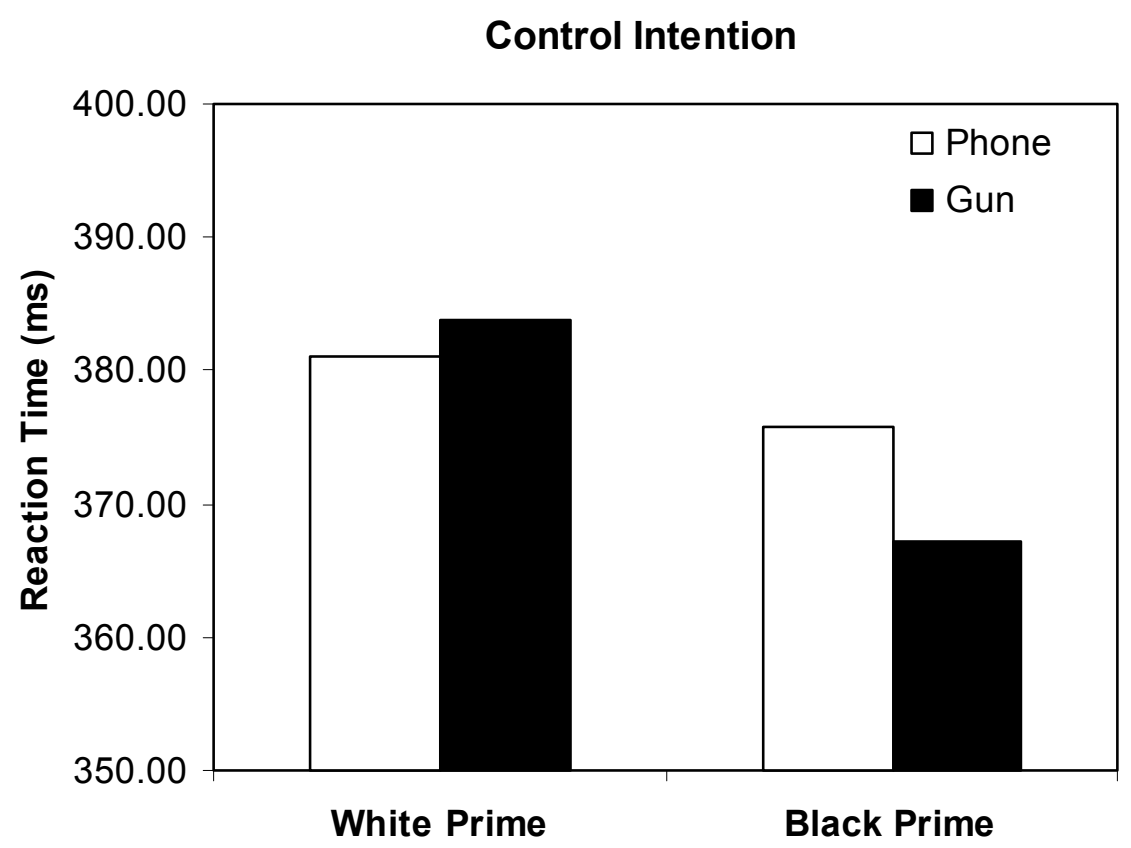

Counter-ste re otypical Intention

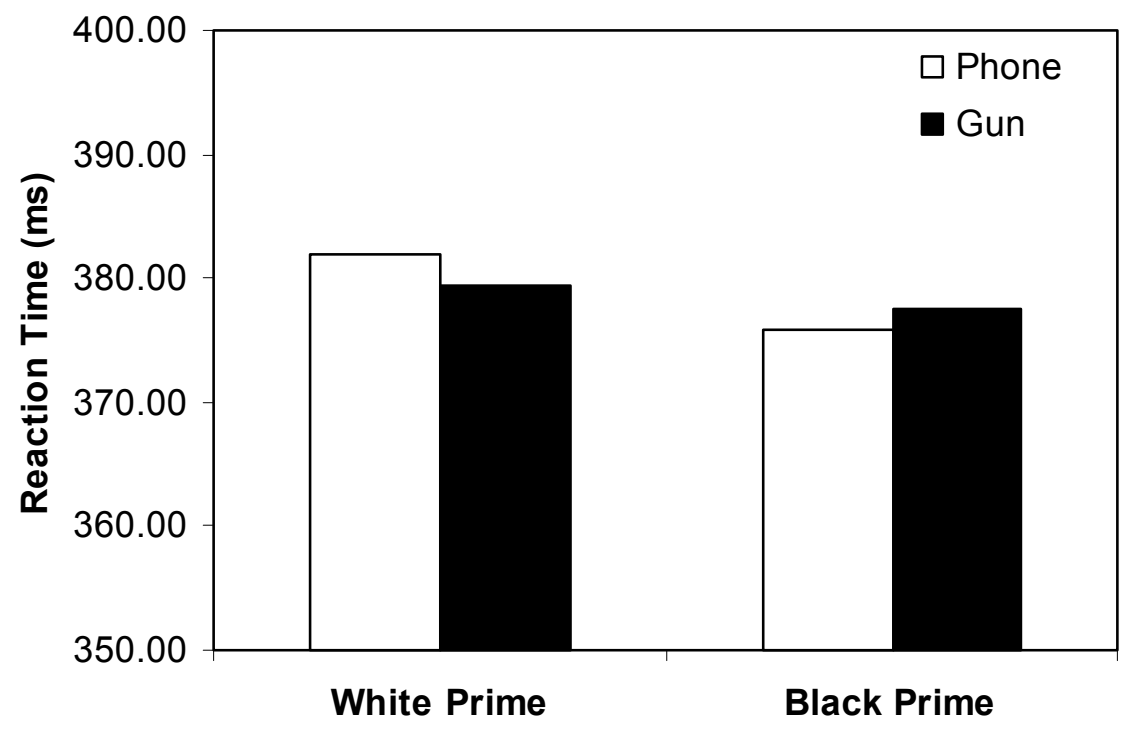

Figure 5.2: Reaction time (re-transformed to milliseconds from log transformed means) as a function of the Race prime, Dot position (after gun or phone), Implementation intention condition (counter-stereotypical versus control), and the $550 \mathrm{~ms}$ condition. 


\section{Discussion}

In the $550 \mathrm{~ms}$ condition, participants in the control intention condition showed stereotype-congruent attentional bias to weapons after being primed with Black faces. This stereotypical attentional bias was eliminated by a counter-stereotypical implementation intention. This reduction in bias at $550 \mathrm{~ms}$ replicated the reduction observed in the previous experiment in which participants saw the gun and phone for 300 ms. At $550 \mathrm{~ms}$, a counter-stereotypical implementation intention seems to have allowed participants to avoid attending to stereotypical objects; participants' attention was either diverted from weapons or they were able to disengage quickly and keep their attention diverted.

In the 250 ms condition, participants in both the counter-stereotypical and control conditions showed attentional bias to weapons regardless of primes. The lack of stereotypical attentional bias in the control condition may be due to a combination of a strong attentional draw of weapons and the nature of the probe detection task with a quick $250 \mathrm{~ms}$ presentation time. It appears that at a very fast presentation time of $250 \mathrm{~ms}$, the general attentional draw of weapons may occur prior to the influence of the social category primes. At a longer presentation time of $550 \mathrm{~ms}$, however, the prime influences attention in the control condition, but this influence is blocked in the counterstereotypical intention condition. These individuals seem to resist the influence of the prime once it occurs and are able to disengage attention from the weapons, even after being primed with Black faces. It is possible that two processes that occur simultaneously create this effect. The counter-stereotypical intention may inhibit stereotypical thoughts, and this process reduces attentional bias to weapons after Black primes. At the same time, 
the guns may draw attention because they are very threatening or because they are so strongly associated with an interracial context in which weapons are to appear that they draw attention when presented with other objects (Kristjansson, 2006). Overall, this strong attentional draw of weapons could produce a general weapon bias at $250 \mathrm{~ms}$ and this bias could be attenuated or eliminated at $550 \mathrm{~ms}$ because the counter-stereotypical intention inhibits stereotypical thoughts and causes disengagement of attention from guns after Black primes. Future research will need to be conducted to test this possibility.

The nature of the probe detection task also may create problems at the short presentation time of $250 \mathrm{~ms}$. The gun and phone photos appear on the outer edge of participants' peripheral vision, and thus, both photos cannot be seen easily at the same time; participants must shift their gaze to one or the other to see the photo clearly. This procedural detail may obscure the biasing effect of the Black and White primes, especially at short stimulus presentation times. If a participant happens to look at the side of the screen with a non-stereotypical object, then there may not be enough time for the stereotypical prime to direct attention to the stereotype-congruent object. This situation may muddy the waters and make it difficult to detect the stereotypical attentional bias effect at fast presentation times.

It also appears that something important may be occurring between the $250 \mathrm{~ms}$ to $300 \mathrm{~ms}$ timeframe. In Experiment 3, participants in the control condition showed stereotypical attentional bias after Black primes, and this effect occurred at $300 \mathrm{~ms}$. In Experiment 4, participants in the control condition did not show stereotypical attentional bias at $250 \mathrm{~ms}$. Finding this difference in stereotypical bias between $250 \mathrm{~ms}$ and 300 $\mathrm{ms}-\mathrm{a} 50 \mathrm{~ms}$ difference - was a bit surprising. One may speculate that the slightly longer 
time allowed participants the extra time needed to fully shift their attention-a saccade (Lee, Zee, \& Straumann, 2000; Snyder, Calton, Dickinson, \& Lawrence, 2002). Thus, if one happened to be looking at the phone initially by chance, the extra time would allow one to survey the screen completely, which would allow the Black prime to direct attention to the gun. In contrast, if one happened to first gaze upon the gun, it may be difficult to shift attention away, especially after the presentation of a Black prime. However, having a counter-stereotypical implementation intention appears to facilitate this disengagement from the guns after Black primes. Although the observed difference between the 250 and 300 ms conditions is interesting, considerable caution must be exercised when making such a comparison of time across experiments. Fifty milliseconds may be psychologically $100 \mathrm{~ms}$ or $150 \mathrm{~ms}$ due to experimenter instructions that differentially emphasize speeded responding or some other subtle difference in the context. 


\section{CHAPTER 6}

\section{GENERAL DISCUSSION}

The abundant evidence supporting the malleability of automatic stereotyping presents an intriguing question about the potential role of conscious goals or intentions in controlling bias. Is the cognitive monster of automatic stereotyping indeed chainable by conscious goals when opportunity to think carefully is limited? An early review of the automatic stereotyping literature indicated that there was not much evidence showing people's ability to control the influence of automatically activated stereotypes and the few promising results required many, many repetitions to learn non-stereotypical responses (Bargh, 1999). Further, the review argued persuasively that meeting all conditions for reducing bias (i.e., awareness of bias, awareness of the magnitude and direction, and motivation and ability to control bias) would occur simultaneously only on rare occasions. Overall, the promise of control did not look bright at that point in time. Shortly after this review, research began to show that automatic or implicit forms of stereotyping were influenced by manipulating the context in which the stimuli appeared, the configuration of the stimuli, or the extent of training to negate stereotypes (Blair et al., 2001; Barden et al., 2004; Kawakami et al., 2000; Lowery et al., 2001; Macrae et al., 1997; Spencer et al., 1998; Wittenbrink et al., 2001).

Although such evidence of situational malleability is suggestive of intentional control, there still is mixed evidence showing that people can intentionally control 
automatic stereotyping, especially in conditions that make control or monitoring responses difficult. For example, some experiments that indirectly induced participants to avoid stereotyping (e.g., interracial interaction; public situation) and those that gave participants an explicit goal to avoid bias have shown increased stereotyping (Lambert, et al., 2003; Payne et al., 2002; Richeson \& Shelton, 2003; Richeson et al., 2003), while a few others indicated that stereotyping may be reduced in certain social interactions (Lowery et al., 2001) or through extensive training (Kawakami et al., 2000). In the current research, I examined the question of the influence of a conscious control strategy on automatic stereotyping and controlled thinking by providing participants with a specific control strategy that required little effort and that they could employ on demand.

I demonstrated that stereotyping was reduced when participants used a counterstereotypical implementation intention. Importantly, the first two experiments demonstrated that this effect was driven by a change in automatic bias. Cognitive control was not increased, as would be expected if participants directed more attention to or concentrated harder on the task. In Experiment 1, I used the weapon identification task to greatly restrict participants' ability to control responses and to determine the separate influences of automatic and controlled thinking within the task. This challenging identification task found that counter-stereotypical implementation intentions reduced stereotyping and this outcome was due to a significant reduction in automatic stereotype bias as assessed by a process dissociation analysis. This finding is notable because it was the first to show a decrease in automatic bias on this task when participants were aware of bias (Payne, 2001; Payne et al., 2002; Lambert et al., 2003). I then conducted a second experiment that ruled out the explanations of practice effects and that participants were 
responding to the specific faces they saw when forming their implementation intentions, instead of responding to the category of African American faces. In Experiment 2, counter-stereotypical implementation intentions generalized to Black faces that participants had not seen in previous trials or while forming their implementation intention.

An important feature of the first two experiments was the use of process dissociation, a technique that does not rely on dissociations between implicit and explicit tasks to estimate automaticity and control. It is important to include methods that do not rely solely on task dissociations to distinguish between automatic and controlled processing because both types of processing can have separate influences within a given task and most implicit measures do not and cannot disentangle these influences (Jacoby, 1991; Payne, Jacoby, \& Lambert, 2005; Roediger, 1990). In regard to this problem of separate influences, research has found that variations in control do influence performance on implicit measures of stereotyping (Payne, 2005). This research found that a low level of cognitive control allows automatic processing to have a greater impact on responses; in addition, research that has impaired participants' controlled thinking by hurrying responses or inducing nervousness, caused automatic bias to exert more influence on participants' responses. Subjective feelings also have been shown to influence implicit measures (Gawronski \& Bodenhausen, 2005). Given the previous findings of the influence of controlled processing and subjective feelings on tasks thought to tap implicit processes, it was important that I used the process dissociation procedure to separate automatic influences from the influences of monitoring and control. 


\section{Alternative Explanations and Potential Mechanisms}

The results of Experiments 1 and 2 verified the explanation that providing participants with a counter-stereotypical response strategy was effective because it decreased automatic accessibility bias when people were aware of the potential for bias and control was difficult. Across both studies, participants were focused on the category of race and potential bias, but those with counter-stereotypical implementation intentions were able to avoid automatic stereotyping. One may wonder if this strategy worked because participants simply were distracted from the relevant category, thus, the stereotype was never made accessible. This explanation is unlikely because the think "quick" control intention should have been just as distracting as the counter-stereotypical intention; therefore, it should have produced non-stereotypical responses similar to the counter-stereotypical intention instead of causing more stereotyping. Furthermore, data from Experiment 2 showed that the social category of the faces was influencing participants in the counter-stereotypical condition; thus, participants were not distracted from the social category information ${ }^{3}$. Finally, the PDP Control estimate should have been decreased if participants in the counter-stereotypical condition were more distracted because they had to expend more cognitive effort to think a thought (i.e., safe) in addition to responding quickly; no such decrease in control was observed. A similar difficulty applies to the explanation that the counter-stereotypical intention limited stereotype activation by causing participants to not attend to the Black and White faces within the weapon identification task. There is no clear explanation for why such a shift would occur for participants in the counter-stereotypical condition, but not the control condition. 
The data from Experiments 1 and 2 also ruled out general semantic priming of "safe" as an alternative explanation. An explanation based upon general semantic priming of "safe" in the counter-stereotypical condition would predict that automatic bias toward responding 'gun' would decrease after both Black and White primes in comparison to the control condition. Instead, in my experiments, bias was lower after Black primes, with no effect on White-prime trials. The effect of the implementation intentions was specific to Black faces. In addition, analyses of log transformed reaction times further supported the conclusion that reduced stereotyping was due to a decrease in automatic bias and not an increase in control. Participants' reaction times in the counter-stereotypical condition were not slower after Black primes when compared to participants' reaction times in the control condition.

The observed decrease in the accessibility of the stereotype raises the interesting possibility that lateral inhibition or negative priming is the mechanism by which counterstereotypical implementation intentions function. Lateral inhibition refers to the unintentional disruption or inhibition of thoughts when those thoughts have been either ignored previously or when one focuses on different thoughts (Bodenhausen \& Macrae, 1998; Neumann \& DeSchepper, 1992; Tipper 2001). In regard to the current research, focusing on a counter-stereotypical thought may cause the relevant stereotypical thought (e.g., dangerous or criminal in the weapon task) to be inhibited. Further, it may be necessary for the specific intentions chosen to be connected to the task-relevant stereotype. Participants with a control implementation intention experienced the same procedure as those with a counter-stereotypical intention, but the control intention did not reduce automatic stereotyping. Since the only difference between the conditions was the 
control intention being unrelated to the relevant stereotypes, it is possible that the thought must be connected to the stereotypes in order for inhibition to occur.

Some research has suggested that the stereotype and thought may in fact need to be connected in the mind of the perceiver for lateral inhibition to occur (Bodenhausen \& Macrae, 1998; Dijksterhuis \& van Knippenberg, 1996). In a series of studies, Macrae, Bodenhausen, and Milne (1995) primed participants with one of two categories (e.g., Chinese or woman) and some participants were given the opportunity to view a video of a person who could be categorized into both categories (e.g., a Chinese woman) and others were not. For example, participants who had been primed with the category of Chinese (e.g., saw chop sticks) showed facilitation for the primed category, and inhibition of the non-primed category (e.g., woman). The non-primed category of woman was relevant to categorizing and stereotyping the Chinese woman, but it was laterally inhibited because the other category was made more accessible through priming. This result may translate to a lateral inhibition mechanism in which a focal, counterstereotypical thought inhibits a relevant stereotype, while a stereotype-irrelevant thought does not. Future research will need to examine this lateral inhibition possibility more thoroughly.

The counter-stereotypical implementation intentions also reduced stereotypical attentional bias (Experiments 3 and 4), and this reduction in bias may have been due to lateral inhibition. In Experiment 3, participants completed a probe detection task in which they were primed with either Black or White faces, were shown pictures of a gun and a phone for $300 \mathrm{~ms}$, and then saw a dot appear where one of the pictures had been. In the control condition, participants showed stereotypical attentional bias. That is, they were 
faster to respond to a dot in the gun location after being primed with Black compared to White faces. This attentional bias was reduced for participants in the counterstereotypical implementation intention condition.

Experiment 4 used the same probe detection task, but varied the length of presentation of the guns and phones. The lessening of stereotypical attentional bias was replicated for participants in the counter-stereotypical condition when guns and phones were presented for a longer period of time $(550 \mathrm{~ms})$. The lack of stereotypical attentional bias at the longer presentation time seems to indicate that counter-stereotypical participants were able to avoid stereotypical bias and were able to maintain this attentional disengagement from weapons. 
The observed drop in bias with the assistance of an implementation intention in Experiments 3 and 4 is consistent with a lateral inhibition mechanism. Imagine a trial in which there is a Black prime, and a participant happens to be looking at the side of the screen that was occupied by the stereotypical object (a gun), and the dot probe is to eventually appear in the location of the gun. The counter-stereotypical implementation intention (think safe) could cause the stereotype of criminal or dangerous to be laterally inhibited. This process would allow these participants to disengage attention from the gun and move it to the phone or the center of the screen; thus, their reaction time would be slowed down to the dot in the gun location after the Black prime. A similar process would occur for the dot in the phone location, but the result would entail a faster reaction to the dot in the phone location because participants' attention would have shifted away from the gun. In the control condition, the Black prime could activate stereotypes, which would influence participants to stay focused on the gun if they had initially focused on the gun. Thus, their reaction time would be faster when the dot was located in the gun location.

\section{Future Directions}

I designed the specific implementation intentions in my studies with the aim of altering automatic responses, and found that they were able to do so in Experiments 1 and 2. A complementary way to reduce stereotypical behavior is to increase control over responses. An interesting question for future research is whether different kinds of implementation intentions aimed at increasing control are similarly effective. For example, an implementation intention might focus participants on the goal of identifying 
weapons accurately ("when I see a Black face, I will try to identify the objects as accurately as I can"). Such an implementation intention might efficiently maximize the use of attention and self-regulation resources, which ultimately may enhance the quality of controlled responding.

Another interesting future direction for this research would be to look at whether a more general implementation intention can be effective. I found that the effect of a counter-stereotypical implementation intention in response to an environmental cue (e.g., category of African American) did generalize to different members of the category that had not been seen previously. Could a broader "then" part of an if-then implementation intention (e.g., an "empathy" or "fairness" intention) reduce stereotyping? If so, the usefulness of the implementation intentions would be enhanced further. Whether such a "broader" intention would be effective is uncertain because my research casts a shadow of doubt upon this possibility. If lateral inhibition is the mechanism by which counterstereotypical implementation intentions function, then it is unlikely that a broad, empathy intention would be effective; this empathy intention would not be connected to the African American social category or the relevant stereotypes, and thus, may not inhibit the relevant stereotypical thoughts. However, it might be possible that a think "positive" intention may be effective if it can counter the negative feelings induced by the criminal or dangerous stereotypes.

\section{Conclusion}

Past research has found evidence supporting both the lack of controllability of stereotyping and the moderation of stereotyping. My research clarifies one way in which 
conscious strategies can be used to overcome stereotypical attentional bias and automatic stereotyping even when all the right circumstances (e.g., opportunity for controlled thinking, awareness, etc.) are not in place. It emphasizes that stereotyping due to difficult conditions may be surmounted if, in advance of an interaction or situation, one can create intentions that link a cognitive response to the relevant situation or group. While this research is encouraging in regard to an individual's ability to alter automatic stereotyping, the results should be noted with caution. The majority of factors known to moderate automatic stereotyping still involve variations in context or responses to context when participants are not alerted to potential bias. Perhaps the most effective approach would change both the social context (increasing positive inter-group contact, friendship, identity salience, etc.), and personal responses to that environment (as the implementation intentions did here). Of course, environmental and societal change is slow and often beyond the control of any one individual. The obstacles to changing such large-scale social environments are well-known. Much less appreciated is the difficulty of changing one's own automatic thinking, which may be almost as difficult as changing environments and other people's thinking. My studies suggest that implementation intentions are a good place to start. 


\section{LIST OF REFERENCES}

Aarts, H., Dijksterhuis, A. P., \& Midden, C. (1999). To plan or not to plan? Goal achievement of interrupting the performance of mundane behaviors. European Journal of Social Psychology, 29, 971-979.

Barden, J., Maddux, W. W., Petty, R. E., \& Brewer, M. B. (2004). Contextual Moderation of Racial Bias: The Impact of Social Roles on Controlled and Automatically Activated Attitudes. Journal of Personality \& Social Psychology, $87,5-22$.

Bargh, J. A. (1999). The cognitive monster: The case against the controllability of automatic stereotype effects. In S. Chaiken, \& Y. Trope (Eds.), Dual-process theories in social psychology (pp. 361-382). New York, NY: The Guilford Press.

Barker, L. A., \& Andrade, J. (2006). Hidden covariation detection produces faster, not slower, social judgments. Journal of Experimental Psychology: Learning, Memory, and Cognition, 32, 636-641.

Blair, I. V. (2002). The Malleability of Automatic Stereotypes and Prejudice. Personality and Social Psychology Review, 6, 242-261.

Blair, I. V., \& Banaji, M. R. (1996). Automatic and controlled processes in stereotype priming. Journal of Personality and Social Psychology, 70, 1142-1163.

Blair, I. V., Ma, J. E., \& Lenton, A. P. (2001). Imagining stereotypes away: The moderation of implicit stereotypes through mental imagery. Journal of Personality \& Social Psychology, 81, 828-841.

Bodenhausen, G. V., \& Macrae, C. N. (1998). Stereotype activation and inhibition. In R. S. Wyer (Ed.), Stereotype activation and inhibition: Advances in social cognition, 11, 1-52. Mahwah, NJ: Lawrence Erlbaum.

Brandstatter, V., Lengfelder, A., \& Gollwitzer, P. M. (2001). Implementation intentions and efficient action initiation. Journal of Personality and Social Psychology, 81, 946-960. 
Bradley, B. P., Mogg, K., Falla, S. J., \& Hamilton, L. R. (1998). Attentional bias for threatening facial expressions in anxiety: Manipulation of stimulus duration. Cognition \& Emotion, 12, 737-753.

Bradley, B. P., Mogg, K., \& Millar, N. H. (2000). Covert and overt orienting of attention to emotional faces in anxiety. Cognition \& Emotion, 14, 789-808.

Burger, J, M., \& Cornelius, T. (2003). Raising the price of agreement: Public commitment and the lowball compliance procedure. Journal of Applied Social Psychology, 33, 923-934.

Connor, C. E., Egeth, H. E., \& Yantis, S. (2004). Visual Attention: Bottom-Up Versus Top-Down. Current Biology, 14, R850-R852.

Dasgupta, N., \& Greenwald, A. G. (2001). On the malleability of automatic attitudes: Combating automatic prejudice with images of admired and disliked individuals. Journal of Personality \& Social Psychology, 81, 800-814.

Dijksterhuis, A., van Knippenberg, A. (1996). The knife that cuts both ways: Facilitated and inhibited access to traits as a result of stereotype activation. Journal of Experimental Social Psychology, 32, 271-288.

Eberhardt, J. L., Goff, P. A., Purdie, V. J., Davies, P. G. (2004). Seeing black: Race, crime, and visual processing. Journal of Personality and Social Psychology, 87, 876-893.

Eysenck, M. W. (1992). Anxiety: The cognitive perspective. Hillsdale, NJ: Lawrence Erlbaum Associates, Inc.

Fazio, R. H. \& Towles-Schwen, T. (1999) The MODE model of attitude-behavior processes. In S. Chaiken, \& Y. Trope (Eds.), Dual-process theories in social psychology (pp. 97-116). New York, NY: The Guilford Press.

Fiske, S. T., Lin, M., \& Neuberg, S. L. (1999). The continuum model: Ten years later. In S. Chaiken, \& Y. Trope (Eds.), Dual-process theories in social psychology (pp. 231-254). New York, NY: The Guilford Press.

Galinsky, A. D., \& Moskowitz, G. B. (2000). Perspective-taking: Decreasing stereotype expression, stereotype accessibility, and in-group favoritism. Journal of Personality \& Social Psychology, 78, 708-724.

Gawronski, B., \& Bodenhausen, G. V. (2005). Accessibility effects on implicit social cognition: The role of knowledge activation and retrieval experiences. Journal of Personality and Social Psychology. 
Gilboa-Schechtman, E., Foa, E. B., Amir, N. (1999). Attentional biases for facial expressions in social phobia: The face-in-the-crowd paradigm. Cognition \& Emotion, 13, 305-318.

Gollwitzer, P. M., \& Brandstatter, V. (1997). Implementation intentions and effective goal pursuit. Journal of Personality and Social Psychology, 73, 186-199.

Gollwitzer, P. M., Fujita, K., Oettingen, G.(2004). Planning and the implementation of goals. Baumeister, R. F., Vohs, K. D., (Eds). In Handbook of self-regulation: Research, theory, and applications. (pp.211-228). New York: Guilford Press.

Gollwitzer, P. M., \& Schaal, B. (1998). Metacognition in action: The importance of implementation intentions. Personality and Social Psychology Review, 2, 124136.

Gollwitzer, P. M., \& Sheeran, P. (2006). Implementation intentions and goal achievement: A meta-analysis of effects and processes. Zanna, M. P., (Ed). In Advances in experimental social psychology. (pp.69-119). Amsterdam: Elsevier.

Gotlib, I. H., McLachlan, A. L., \& Katz, A. N. (1988). Biases in visual attention in depressed and nondepressed individuals. Cognition \& Emotion, 2, 185-200.

Govorun, O., \& Payne, B. K. (2006). Ego-depletion and prejudice: Separating automatic and controlled components. Social Cognition, 24, 111-136.

Grill-Spector, K., Kushnir, T., Hendler, T., \& Malach, R. (2000). The dynamics of object-selective activation correlate with recognition performance in humans. Nature Neuroscience, 3, 837-843.

Hense, R. L., Penner, L. A., \& Nelson, D. L. (1995). Implicit memory for age stereotypes. Social Cognition, 13, 399-415.

Jacoby, W. G. (1991). Data theory and dimensional analysis. Thousand Oaks, CA: Sage Publications, Inc.

Kawakami, K., Dovidio, J. F., Moll, J., Hermsen, S., \& Russin, A. (2000). Just say no (to stereotyping): Effects of training in the negation of stereotypic associations on stereotype activation. Journal of Personality \& Social Psychology, 78, 871-888.

Kiesler, C. A. (1971). The psychology of commitment. New York: Academic Press.

Kristjansson, A. (2006). Simultaneous priming along multiple feature dimensions in a visual search task. Vision Research, 46, 2554-2570. 
Kristjansson, A., Wang, D., \& Nakayama, K. (2002). The role of priming in conjunctive visual search. Cognition, 85, 37-52.

Kunda, Z., \& Spencer, S. J. (2003). When do stereotypes come to mind and when do they color judgment? A goal-based theoretical framework for stereotype activation and application. Psychological Bulletin, 129, 522-544.

Lambert, Alan J. Payne, B. K., Jacoby, Larry L., Shaffer, Lara M., Chasteen, Alison, L., \& Khan, Saera, R. (2003). Stereotypes as dominant responses: On the "social facilitation" of prejudice in anticipated public contexts. Journal of Personality \& Social Psychology, 84, 277-295.

Lee, C., Zee, D. S., \& Straumann, D. (2000). Saccades from torsional offset positions back to Listing's plane. Journal of Neurophysiology, 83, 3241-3253.

Lewicki, P., Hill, T., \& Czyzewska, M. (1997). Hidden covariation detection: A fundamental and ubiquitous phenomenon. Journal of Experimental Psychology: Learning, Memory, and Cognition, 23, 221-228.

Liberman, N., \& Foerster, J. (2000). Expression after suppression: A motivational explanation of postsuppressional rebound. Journal of Personality \& Social Psychology, 79, 190-203.

Lowery, B. S., Hardin, C. D., \& Sinclair, S. (2001). Social influence effects on automatic racial prejudice. Journal of Personality \& Social Psychology, 81, 842-855.

MacLeod, C., Mathews, A., \& Tata, P. (1986). Attentional bias in emotional disorders. Journal of Abnormal Psychology, 95, 15-20.

Macrae, C. N., \& Bodenhausen, G. V. (2000). Social cognition: Thinking categorically about others. Annual Review of Psychology, 51, 93-120.

Macrae, C. N., Bodenhausen, G.V., Milne, A. B. (1995). The dissection of selection in person perception: Inhibitory processes in social stereotyping. Journal of Personality \& Social Psychology, 69, 397-407.

Macrae, C. N., Bodenhausen, G. V., Milne, A. B., \& Jetten, J. (1994). Out of mind but back in sight: Stereotypes on the rebound. Journal of Personality \& Social Psychology, 67, 808.

Macrae, C. N., Bodenhausen, G. V., Milne, A.B., Thorn, T. M. J., \& Castelli, L. (1997). On the activation of social stereotypes: The moderating role of processing objectives. Journal of Experimental Social Psychology, 33, 471. 
Mansell, W., Clark, D. M., Ehlers, A., \& Chen, Y-P. (1999). Social anxiety and attention away from emotional faces. Cognition \& Emotion, 13, 673-690.

Mathews, A., \& MacLeod, C. (1985). Selective processing of threat cues in anxiety states. Behaviour Research and Therapy, 23, 563-569.

Mitchell, J. P., Nosek, B. A., \& Banaji, M. R. (2003). Contextual variations in implicit evaluation. Journal of Experimental Psychology: General, 132, 455-469.

Mogg, K., \& Bradley, B. P. (1999). Some methodological issues in assessing attentional biases for threatening faces in anxiety: A replication study using a modified version of the probe detection task. Behaviour Research and Therapy, 37, 595604.

Monteith, M.J., Ashburn-Nardo, L., Voils, C. I., Czopp, A. M. (2002). Putting the brakes on prejudice: On the development and operation of cues for control. Journal of Personality \& Social Psychology, 83, 1029-1050.

Neumann, E., \& Deschepper, B.G. (1992). An inhibition-based fan effect: Evidence for an active suppression mechanism in selective attention. Canadian Journal of Psychology, 46,1-40.

Oe, T., \& Oka, T. (2003). Overcoming the ironic rebound: Effective and ineffective strategies for stereotype suppression. In K-S. Yang, K-K. Hwang, P. B. Pedersen, \& I. Daibo (Eds.), Progress in Asian social psychology. (pp. 233-246). Westport, CT: Praeger.

Ouellette, J. A. \& Wood, W. (1998). Habit and intention in everyday life: The multiple processes by which past behavior predicts future behavior. Psychological Bulletin, 124, 54-74.

Payne, B. K. (2001). Prejudice and perception: The role of automatic and controlled processes in misperceiving a weapon. Journal of Personality and Social Psychology, 81, 181-192.

Payne, B. K. (2005). Conceptualizing control in social cognition: How executive functioning modulates the expression of automatic stereotyping. Manuscript submitted for publication.

Payne, B. K., Jacoby, L. L., Lambert, A. J. (2004). Memory monitoring and the control of stereotype distortion. Journal of Experimental Social Psychology, 40, 52-64.

Payne, B. K., Jacoby, L. L., \& Lambert, A. J. (2005). Attitudes as Accessibility Bias: Dissociating Automatic and Controlled Processes. In J. Bargh (Ed.), The new unconscious (pp. 393-420). Oxford University Press: New York, NY. 
Payne, B. K., Lambert, A. J., Jacoby, L. L. (2002). Best laid plans: Effects of goals on accessibility bias and cognitive control in race-based misperceptions of weapons. Journal of Experimental Social Psychology, 38, 384-396.

Payne, B. K., Shimizu, Y., \& Jacoby, L. L. (2005). Mental control and visual illusions: Toward explaining race-biased weapon misidentifications. Journal of Experimental Social Psychology, 41, 36-47.

Pickel, K L., Ross, S. J., \& Truelove, R. S. (2006). Do Weapons Automatically Capture Attention? Applied Cognitive Psychology, 20, 871-893.

Plant, E. A., Peruche, B. M., \& Butz, D. A. (2005). Eliminating automatic racial bias: Making race non-diagnostic for responses to criminal suspects. Journal of Experimental Social Psychology, 41, 141-156.

Richeson, J. A., Baird, A.A., Gordon, H.L., Heatherton, T.F., Wyland, C. L., Trawalter, S.; \& Shelton, J. N. (2003). An fMRI investigation of the impact of interracial contact on executive function. Nature Neuroscience, 6, 1323-1328.

Richeson, J. A, \& Shelton, J. N. (2003). When prejudice does not pay: Effects of interracial contact on executive function. Psychological Science, 14, 287-290.

Richeson, J. A., \& Trawalter, S. (2005). Why Do Interracial Interactions Impair Executive Function? A Resource Depletion Account. Journal of Personality and Social Psychology, 88, 934-947.

Roediger, H.L. (1990). Implicit memory: A commentary. Bulletin of the Psychonomic Society, 28, 373-380.

Roskos-Ewoldsen, D. R., \& Fazio, R. H. (1992). On the orienting value of attitudes: Attitude accessibility as a determinant of an object's attraction of visual attention. Journal of Personality and Social Psychology, 63, 198-211.

Serences, J. T., Shomstein, S., Leber, A. B., Golay, X., Egeth, H. E., \& Yantis, S. (2005). Coordination of voluntary and stimulus-driven attentional control in human cortex. Psychological Science, 16, 114-122.

Shaw, J. I., \& Skolnick, P. (1999). Weapon focus and gender differences in eyewitness accuracy: Arousal versus salience. Journal of Applied Social Psychology, 29, 2328-2341.

Sherman, J. W., Conrey, F. R., \& Groom, C. J. (2004). Encoding flexibility revisited: Evidence for enhanced encoding of stereotype-inconsistent information under cognitive load. Social Cognition, 22, 214-232. 
Sherman, J. W., Lee, A. Y., Bessenoff, G. R., \& Frost, L. A. (1998). Stereotype efficiency reconsidered: Encoding flexibility under cognitive load. Journal of Personality and Social Psychology, 75, 589-606.

Sinclair, L., \& Kunda, Z. (1999). Reactions to a Black professional: Motivated inhibition and activation of conflicting stereotypes. Journal of Personality \& Social Psychology, 77, 885-904.

Sinclair, S., Lowery, B. S., Hardin, C. D., \& Colangelo, A. (2005). Social Tuning of Automatic Racial Attitudes: The Role of Affiliative Motivation. Journal of Personality and Social Psychology, 89, 583-592.

Snyder, L. H., Calton, J. L., Dickinson, A. R., \& Lawrence, B. M. (2002). Eye-hand coordination: Saccades are faster when accompanied by a coordinated arm movement. Journal of Neurophysiology, 87, 2279-2286.

Spencer, S.J., Fein, S., Wolfe, C.T., Fong, C., \& Dunn, M.A. (1998). Automatic activation of stereotypes: The role of self-image threat. Personality \& Social Psychology Bulletin, 24, 1139-1152.

Steblay, N. M. (1992). A meta-analytic review of the weapon focus effect. Law and Human Behavior, 16, 413-424.

Tipper, S.P. (2001). Does negative priming reflect inhibitory mechanisms? A review and integration of conflicting views. Quarterly Journal of Experimental Psychology: Human Experimental Psychology, 54, 321-343.

Tooley, V., Brigham, J. C., Maass, A., \& Bothwell, R. K. (1987). Facial recognition: Weapon effect and attentional focus. Journal of Applied Social Psychology, 17, 845-859.

Webb, T. L., \& Sheeran, P. (2007). How do implementation intentions promote goal attainment? A test of component processes. Journal of Experimental Social Psychology, 34, 295-302.

Wilson, T. D., \& Brekke, N. (1994). Mental contamination and mental correction: Unwanted influences on judgments and evaluations. Psychological Bulletin, 116, 117-142.

Wittenbrink, B., Judd, C. M., \& Park, B. (2001). Spontaneous prejudice in context: Variability in automatically activated attitudes. Journal of Personality \& Social Psychology, 81, 815-827. 
Wolfe, J. M., Butcher, S. J., Lee, C., \& Hyle, M. (2003). Changing your mind: On the contributions of top-down and bottom-up guidance in visual search for feature singletons. Journal of Experimental Psychology: Human Perception and Performance, 29, 483-502. 


\section{ENDNOTES}

${ }^{1}$ The instructions used in this experiment replicate conceptually the if-then format that is theorized to be the driving force behind the effectiveness of implementation intentions. According to the theory, an if-then format links an environmental stimulus with a specific response (e.g., when I see a Black face, I will then think 'safe'). The creation of this link increases the accessibility of both the environmental stimulus, and the specific thought or intention to which it was linked. Although technically I used a "when-then" format rather than an "if-then" format, it would make little sense to participants to use "if" rather than "when" in the context of a task in which it was clear that they would see both Black and White faces repeatedly. Gollwitzer and colleagues have successfully used this same format in previous studies (e.g., Brandstatter et al., 2001). My manipulation of implementation intentions makes the environmental stimulus (i.e., a Black face) accessible, and makes the thought that was linked to the stimulus accessible when the appropriate face is encountered.

${ }^{2}$ Some bias in preference of looking at the left or right side of the screen can increase error variance on the probe detection task because the pictures of objects are at the edge of participants' peripheral vision (Mogg \& Bradley, 1999). The "side" variable was included in the previous analyses to reduce this error variance and obtain more power, but this variable was not expected to interact with the other variables. As predicted, the Intention $\mathrm{x}$ Prime $\mathrm{x}$ Dot Position $\mathrm{x}$ Side interaction was non-significant, $F(1,100)=1.04$, $p=.310$.

${ }^{3}$ In Experiment 2, simple effects tests showed that automatic stereotype bias (i.e., higher "gun" bias after Black primes than after White primes) was significant in the counterstereotypical condition $(M=.58, M=.51$; Table 3.1 on page 36$)$. However, the automatic bias after Black primes was significantly smaller in the counter-stereotypical intention condition $(M=.58 ; S D=.19)$ when compared to the control condition $(M=$ $.70 ; S D=.15)$. No difference between the control and counter-stereotypical conditions was found for automatic bias after White prime, $F<1$. 
APPENDIX A: MATERIALS USED IN EXPERIMENT 1

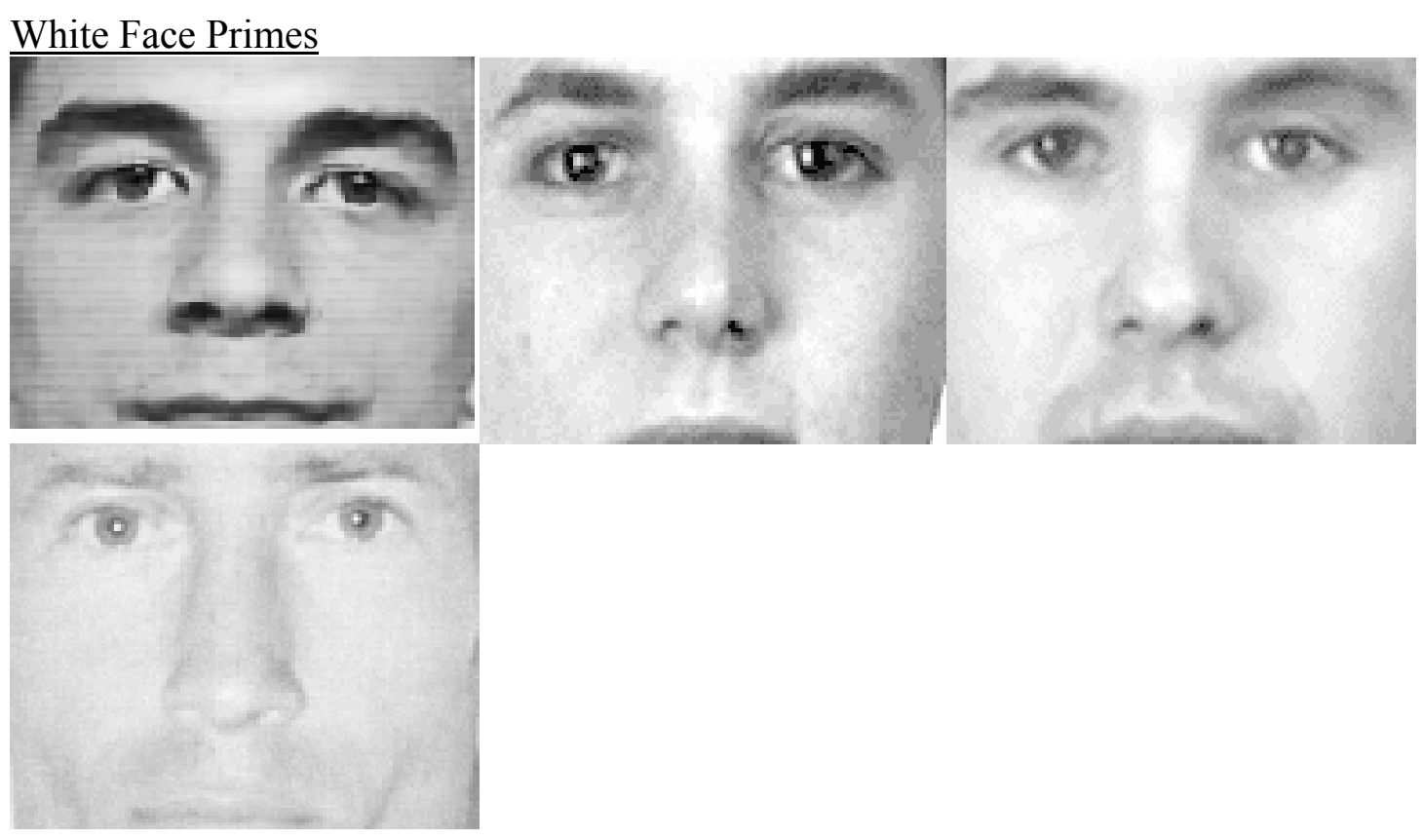

\section{$\underline{\text { Black Face Primes }}$}

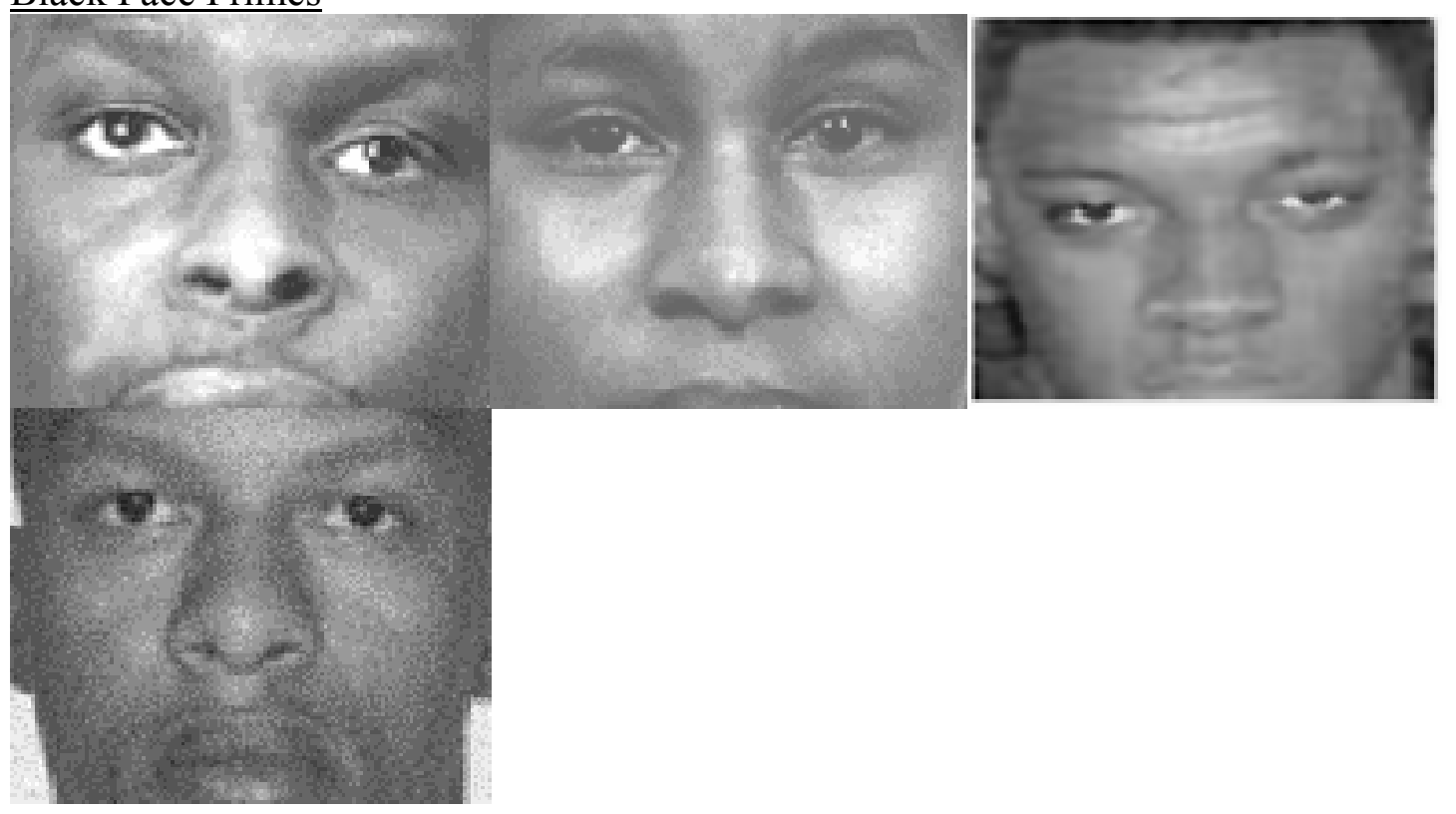


$\underline{\text { Guns }}$
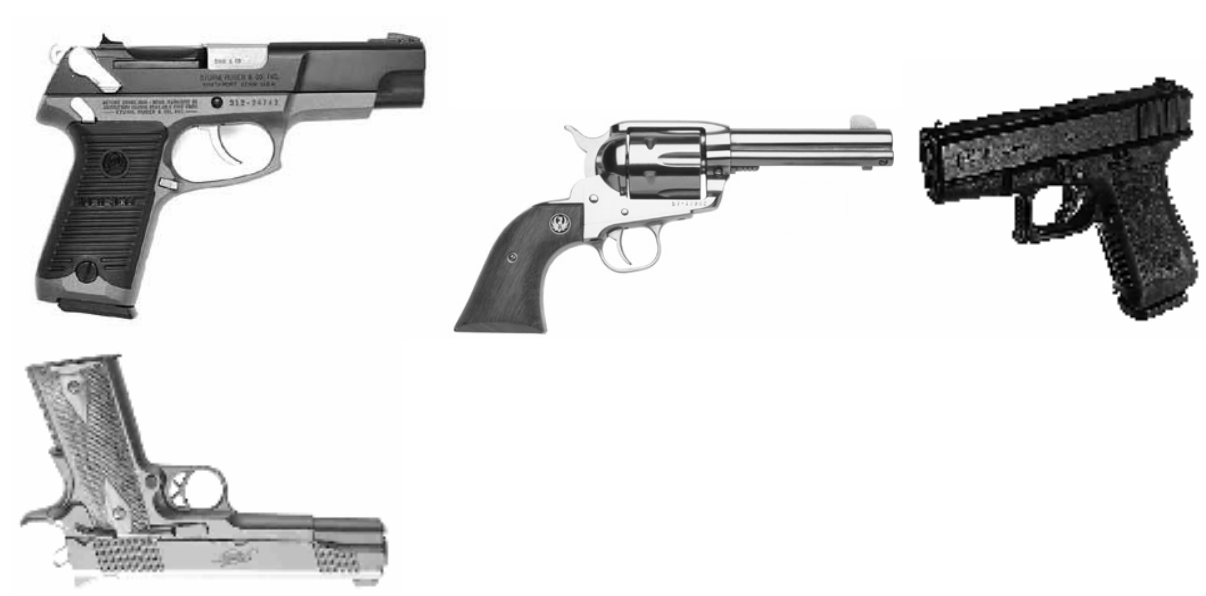

$\underline{\text { Tools }}$
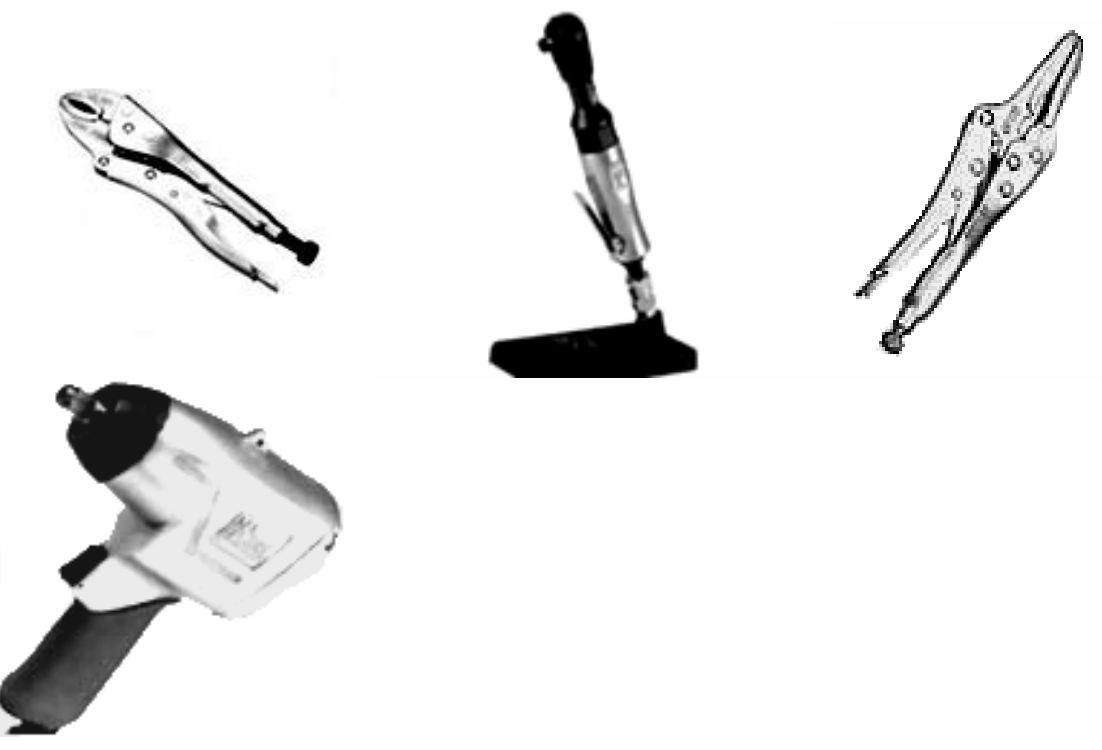
APPENDIX B: MATERIALS USED IN EXPERIMENT 2

\section{Practiced Faces}
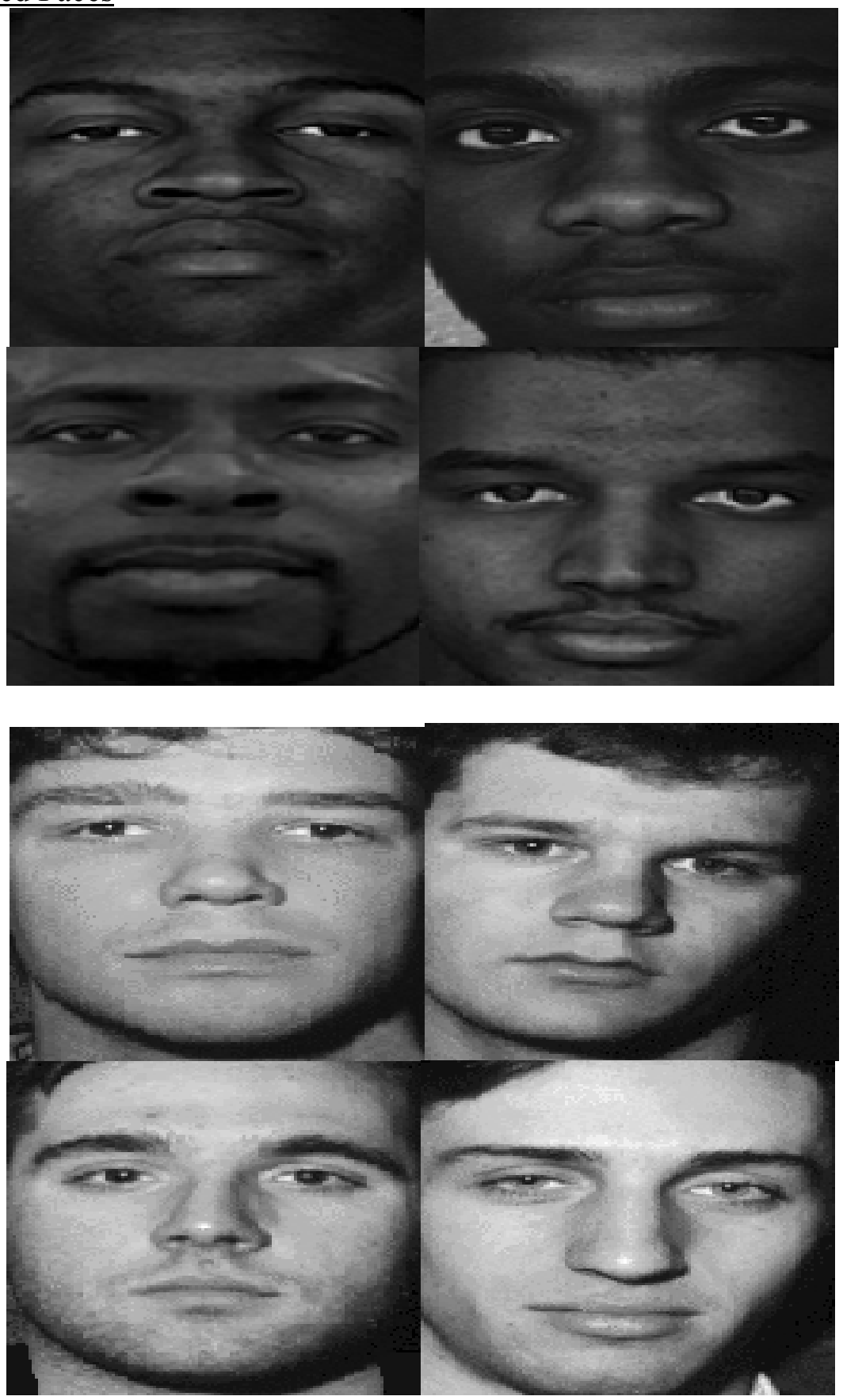
Novel Faces
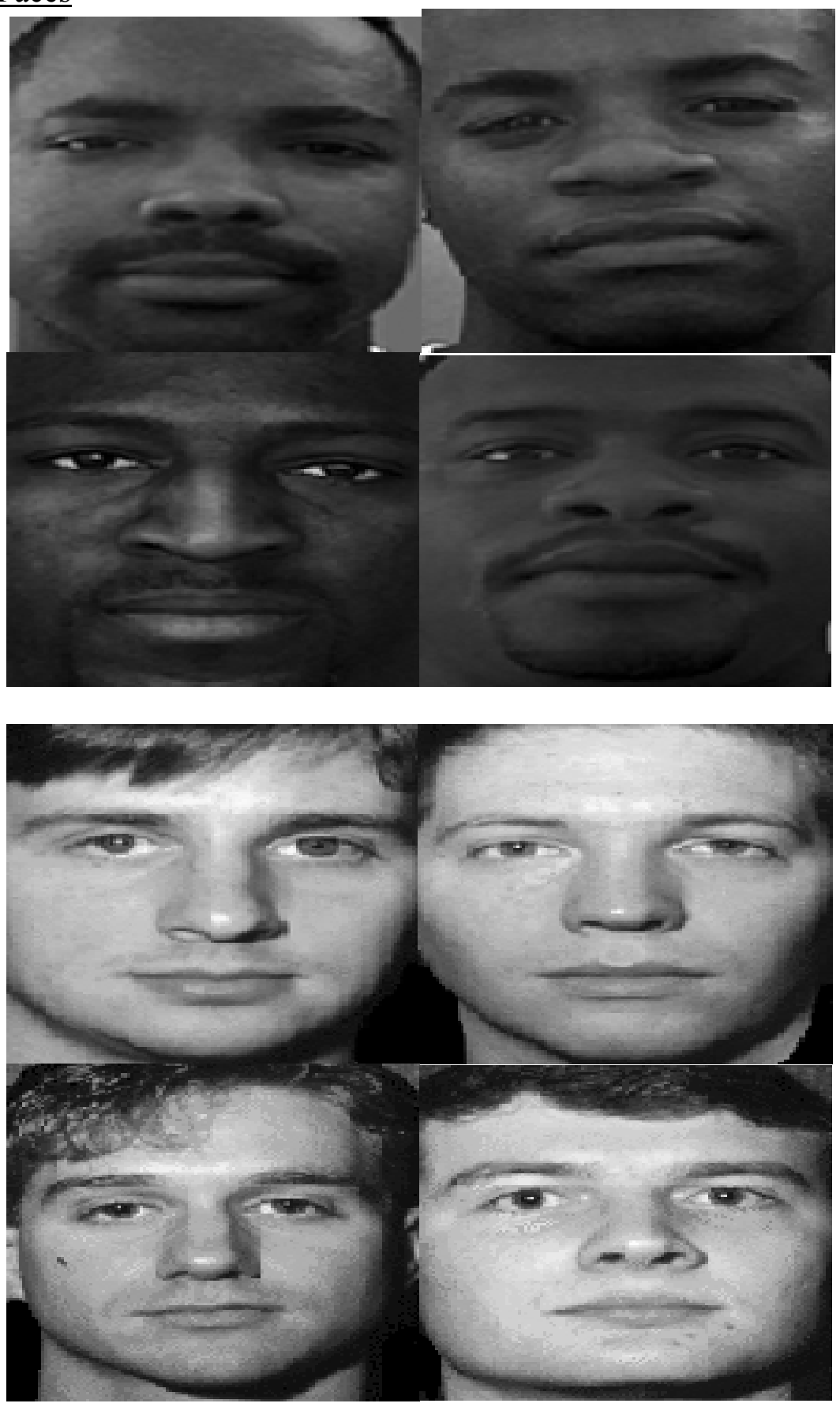
APPENDIX C: $\quad$ FACE PRIMES USED IN EXPERIMENT 3

\section{Black Face Primes}

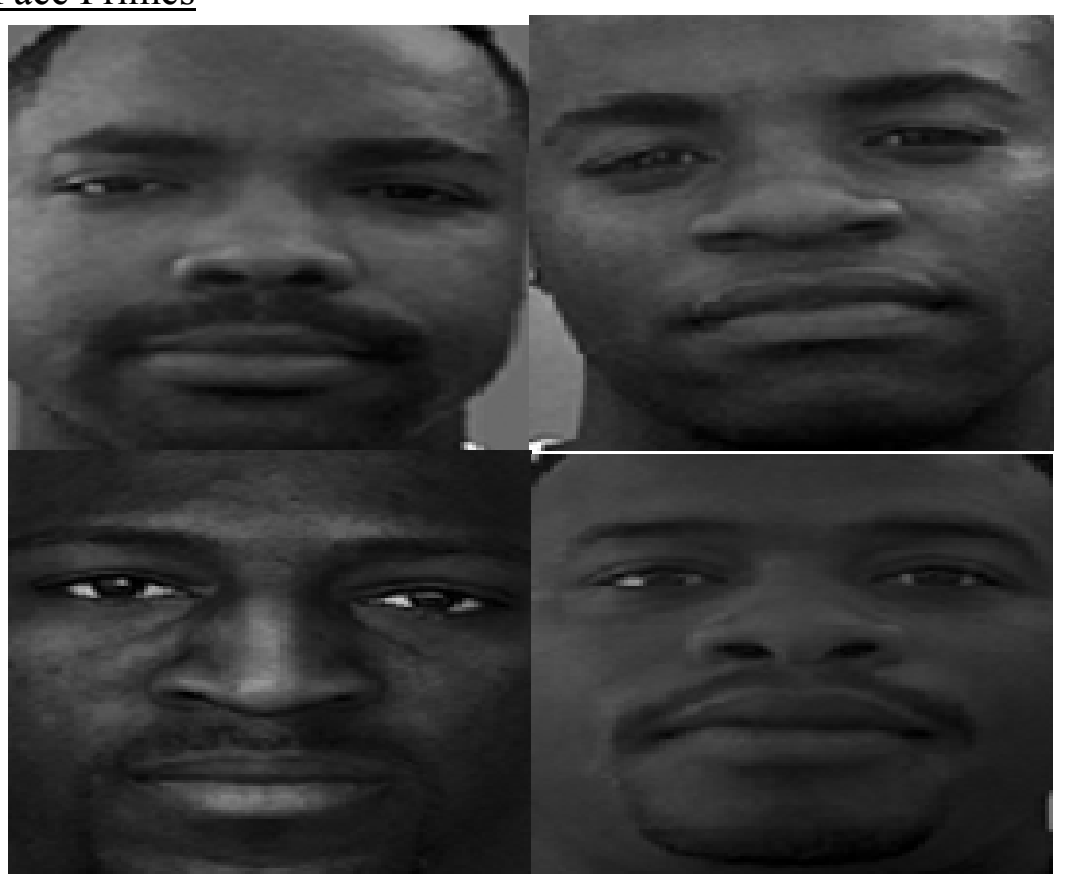

White Face Primes

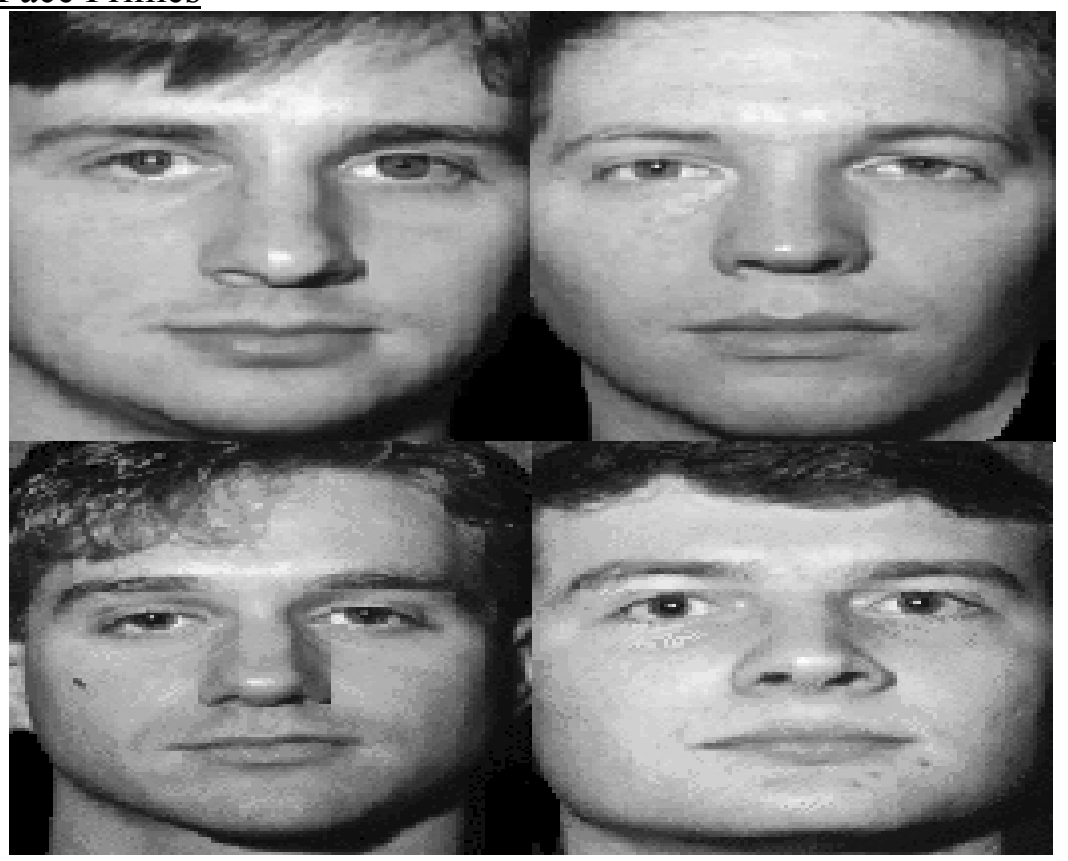


APPENDIX D: GUNS AND PHONES USED IN EXPERIMENT 3 

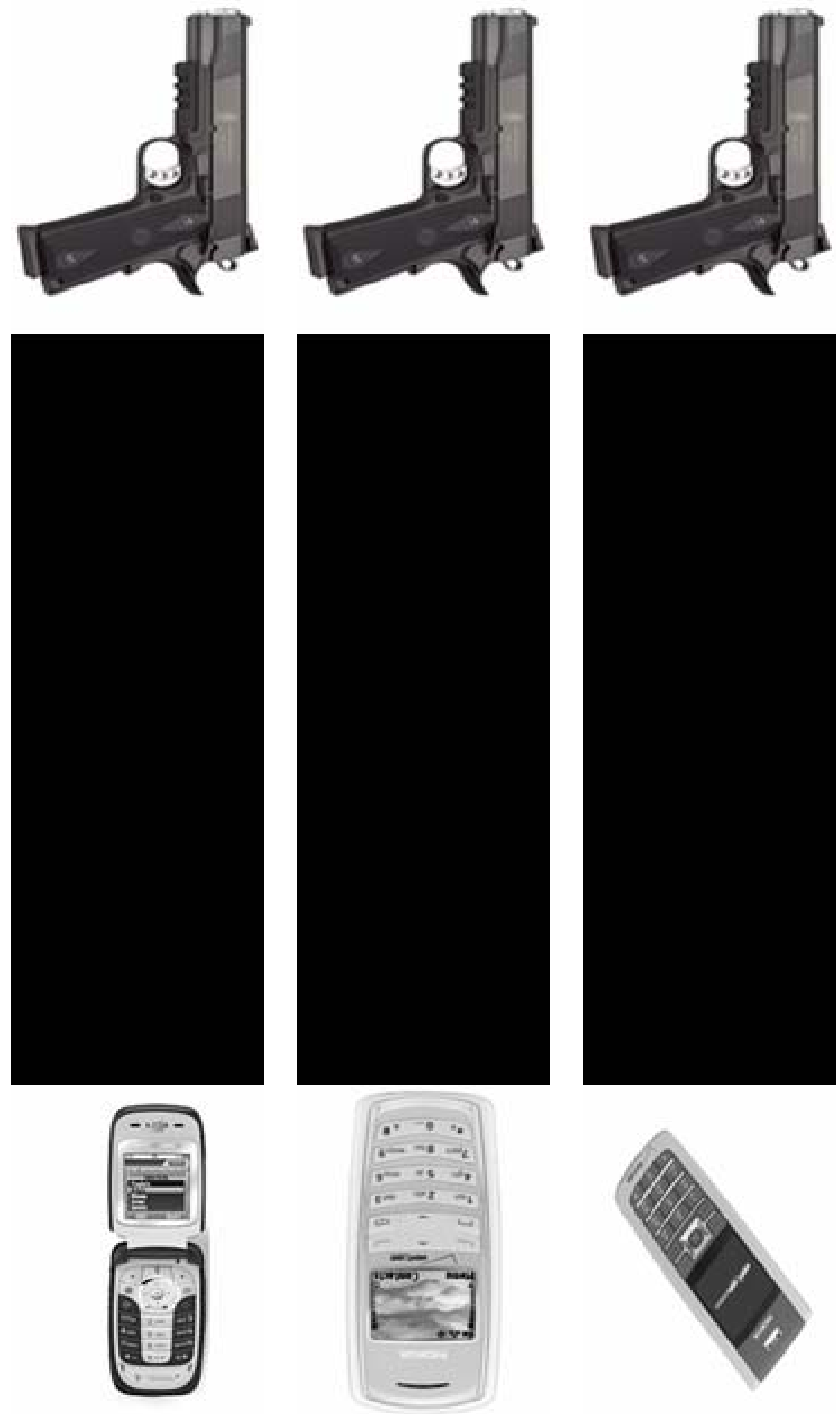

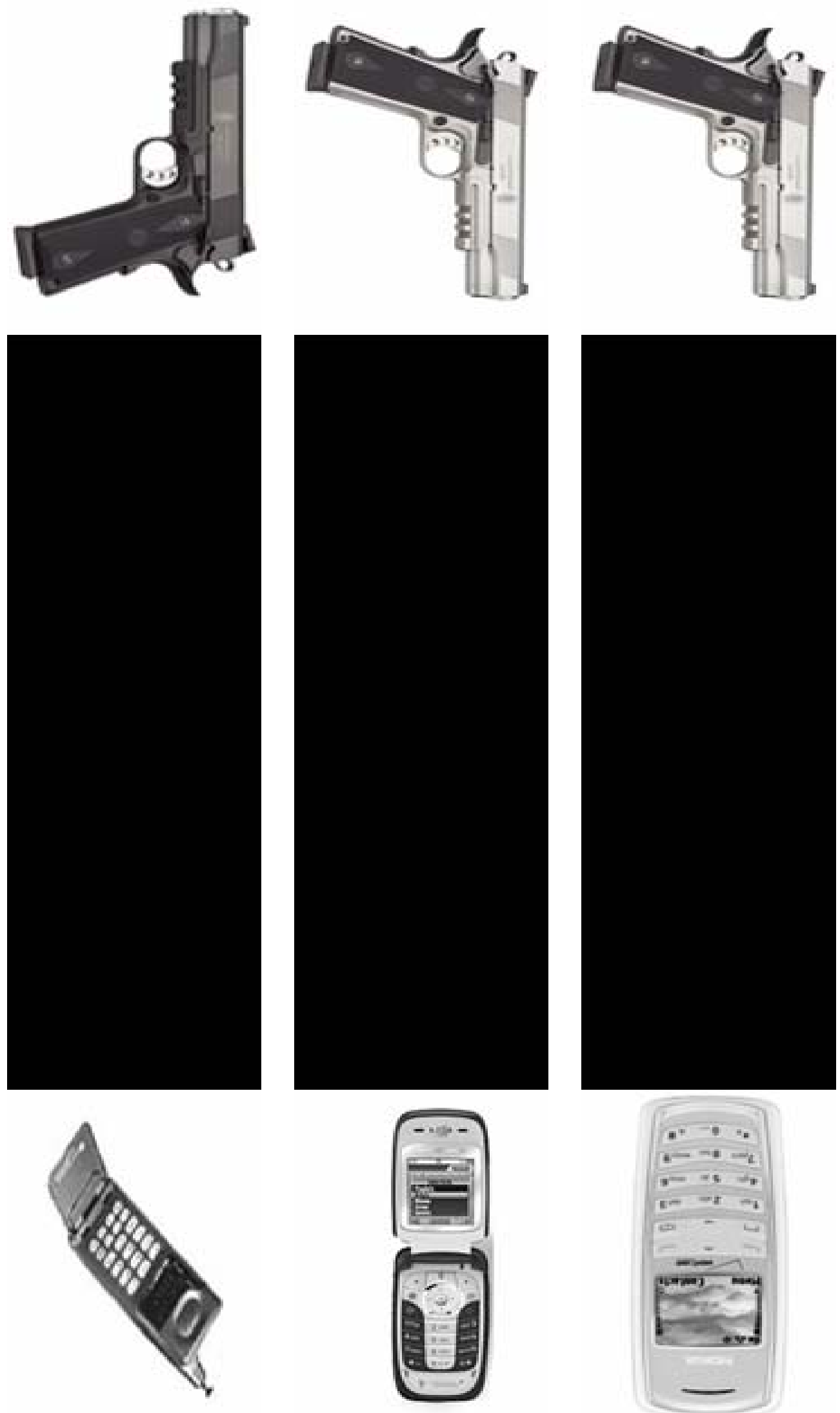

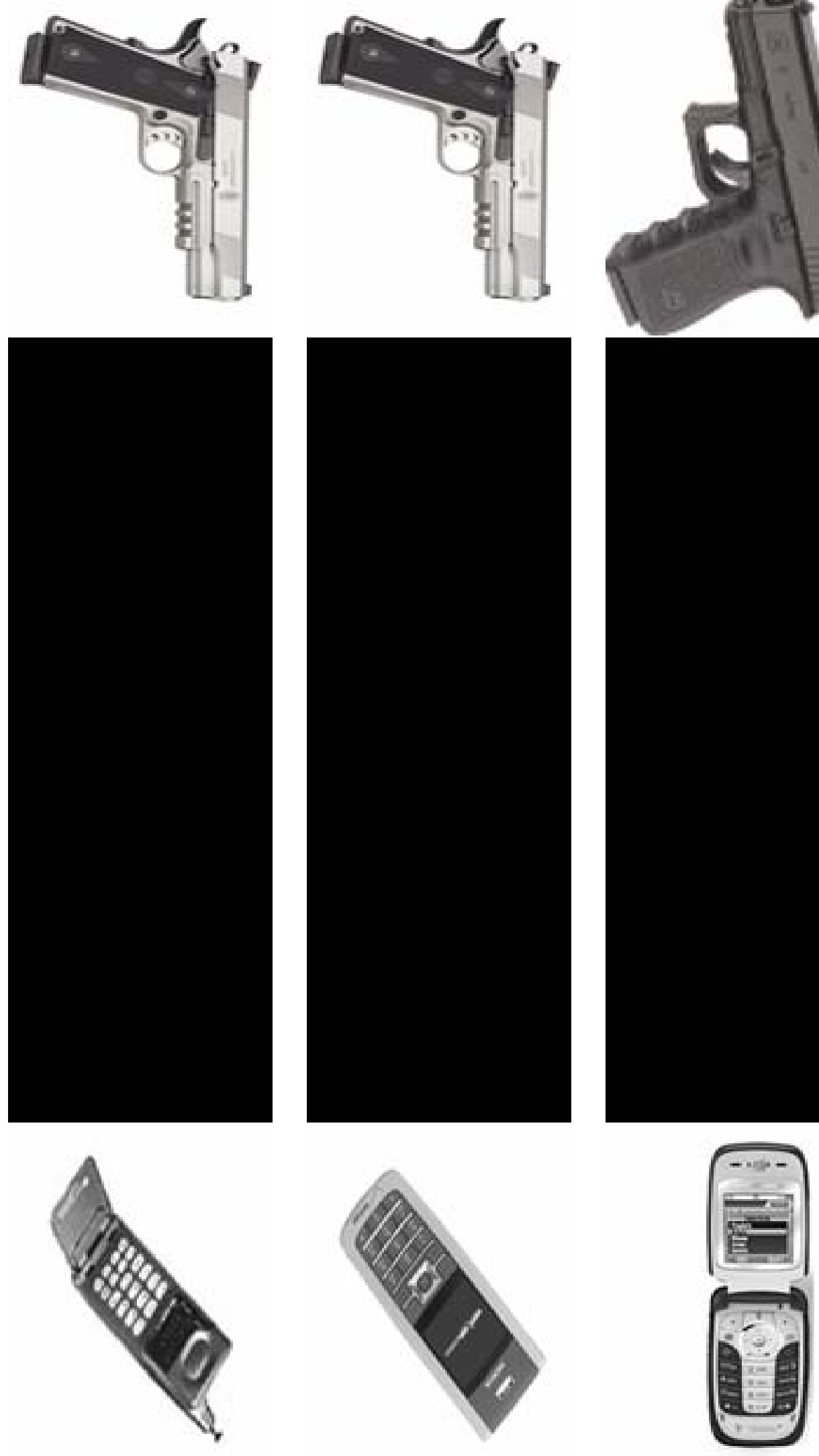

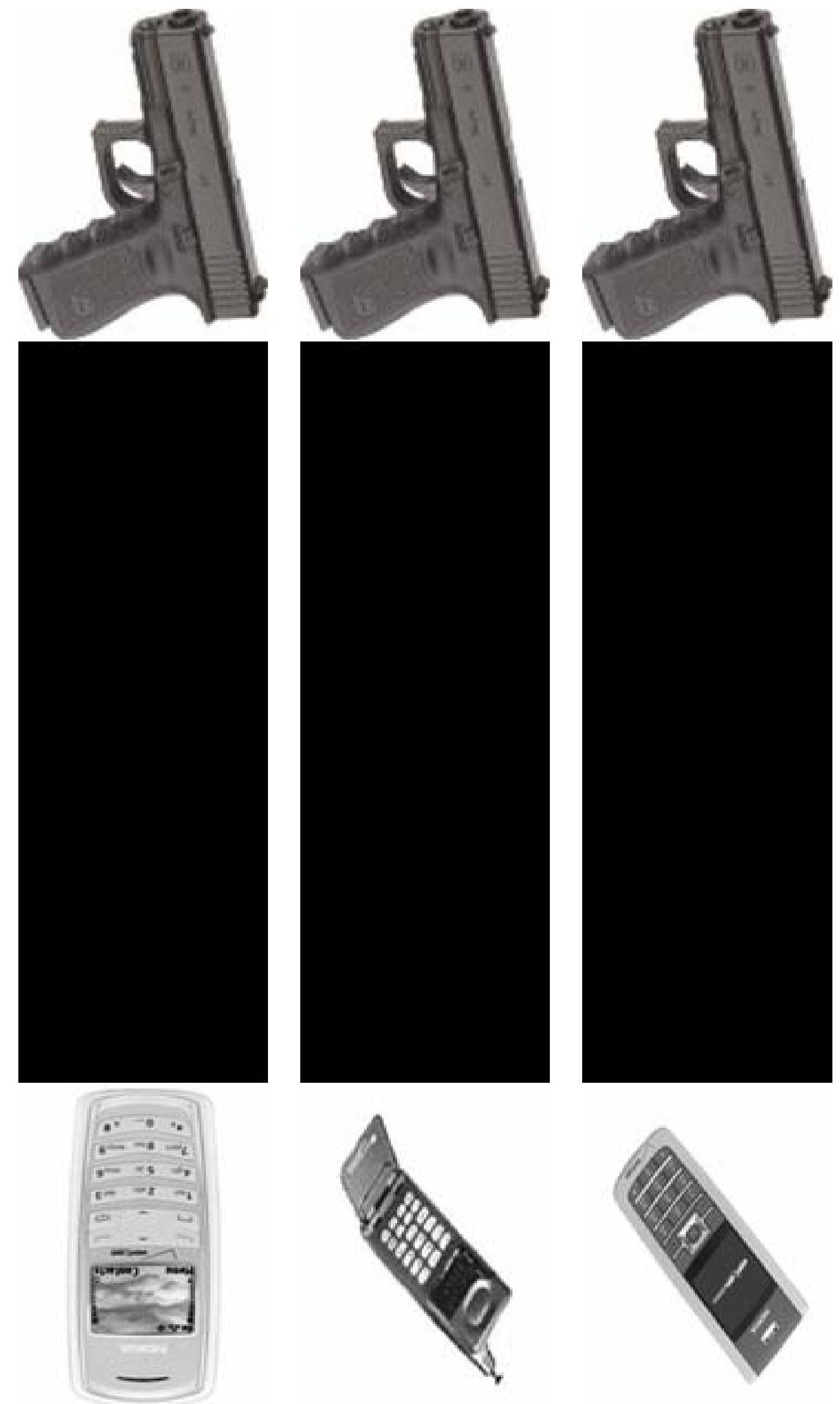

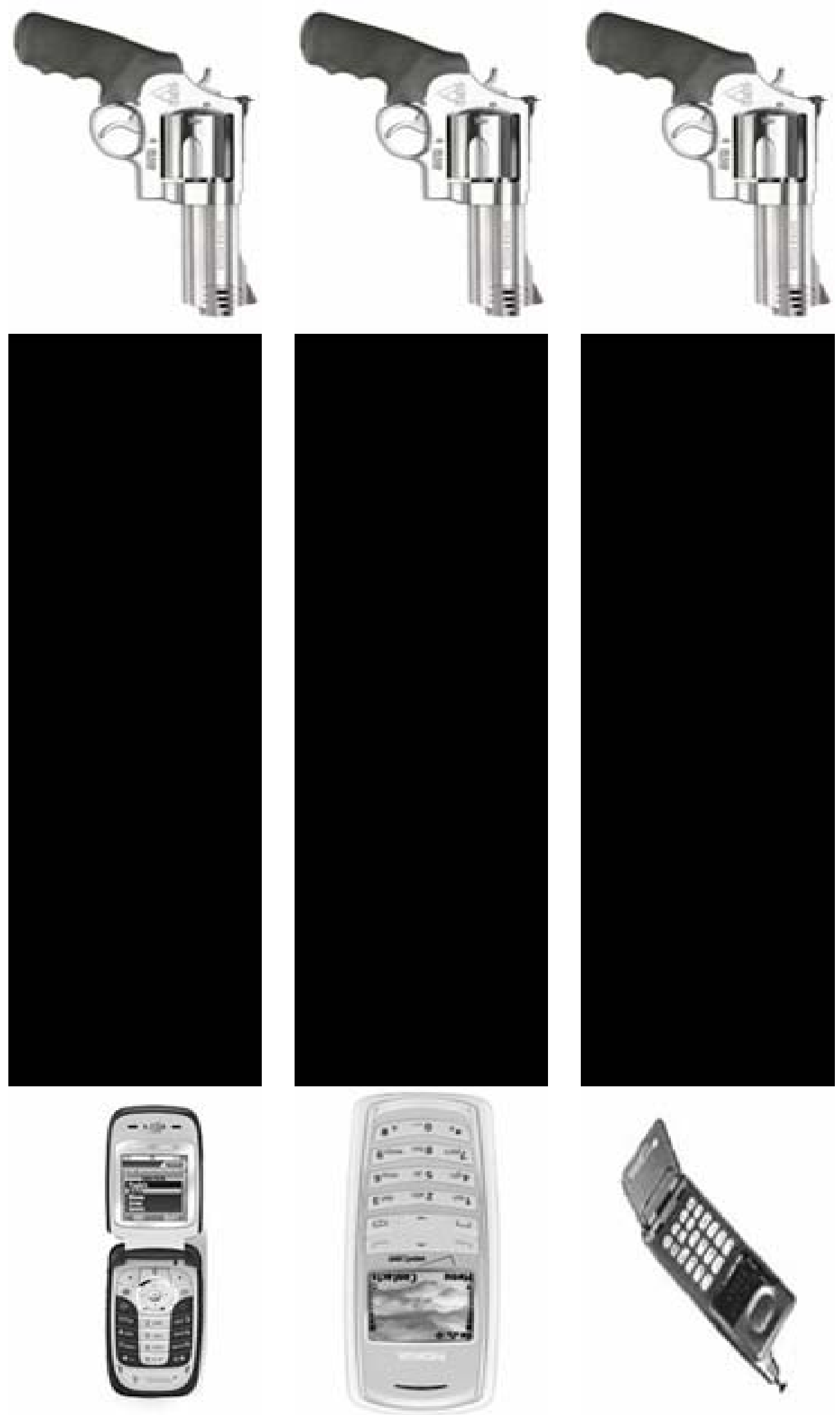

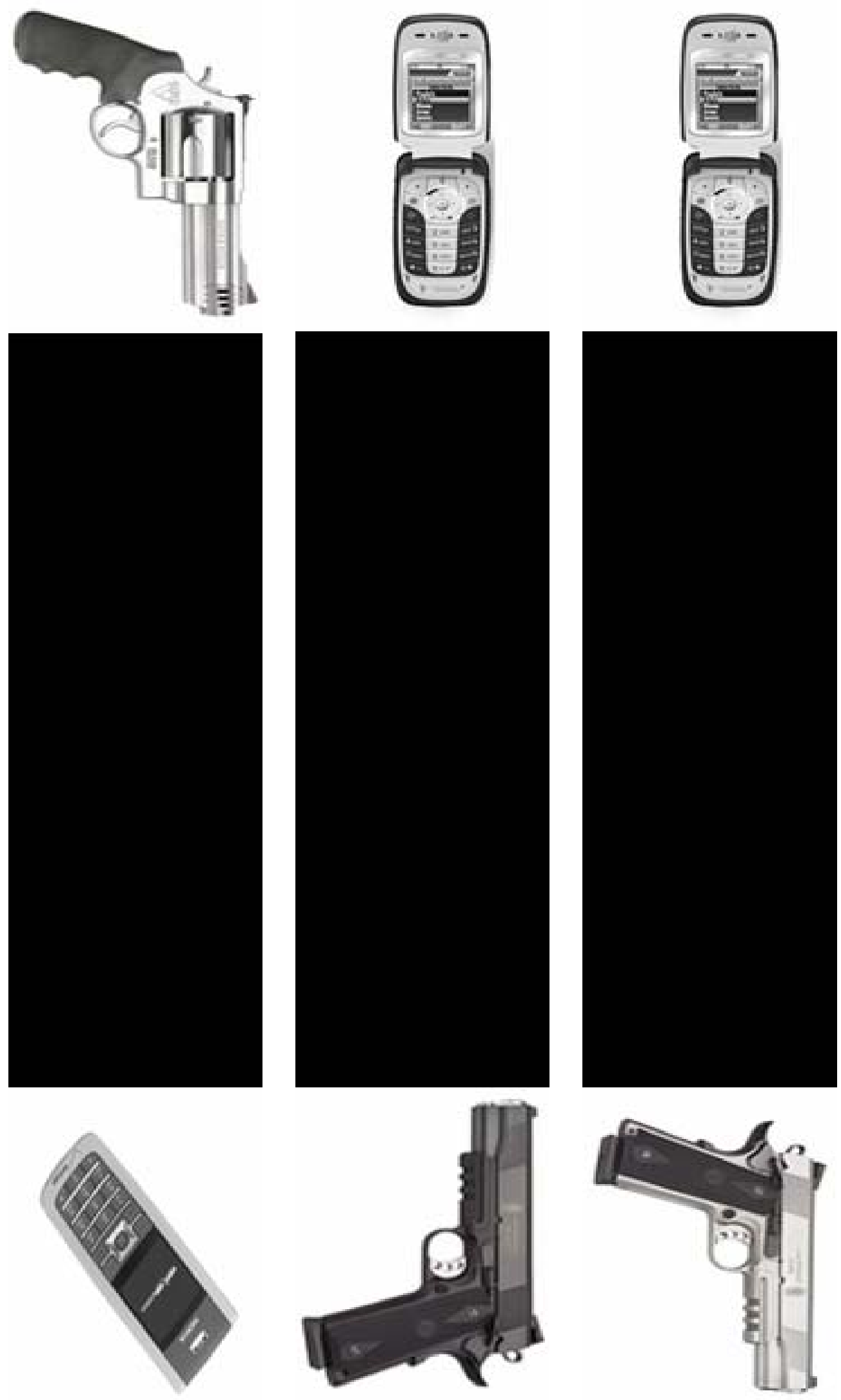


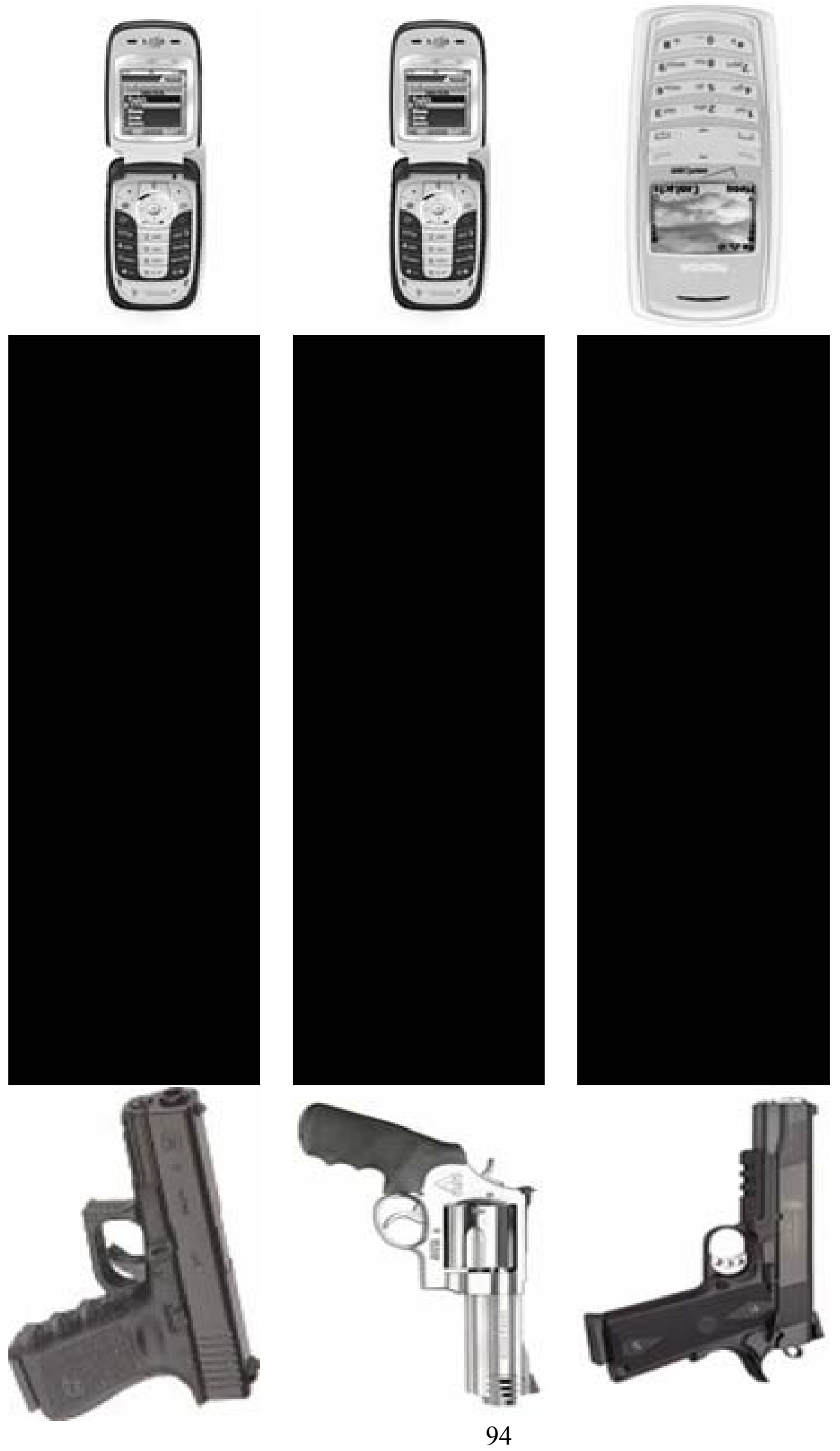




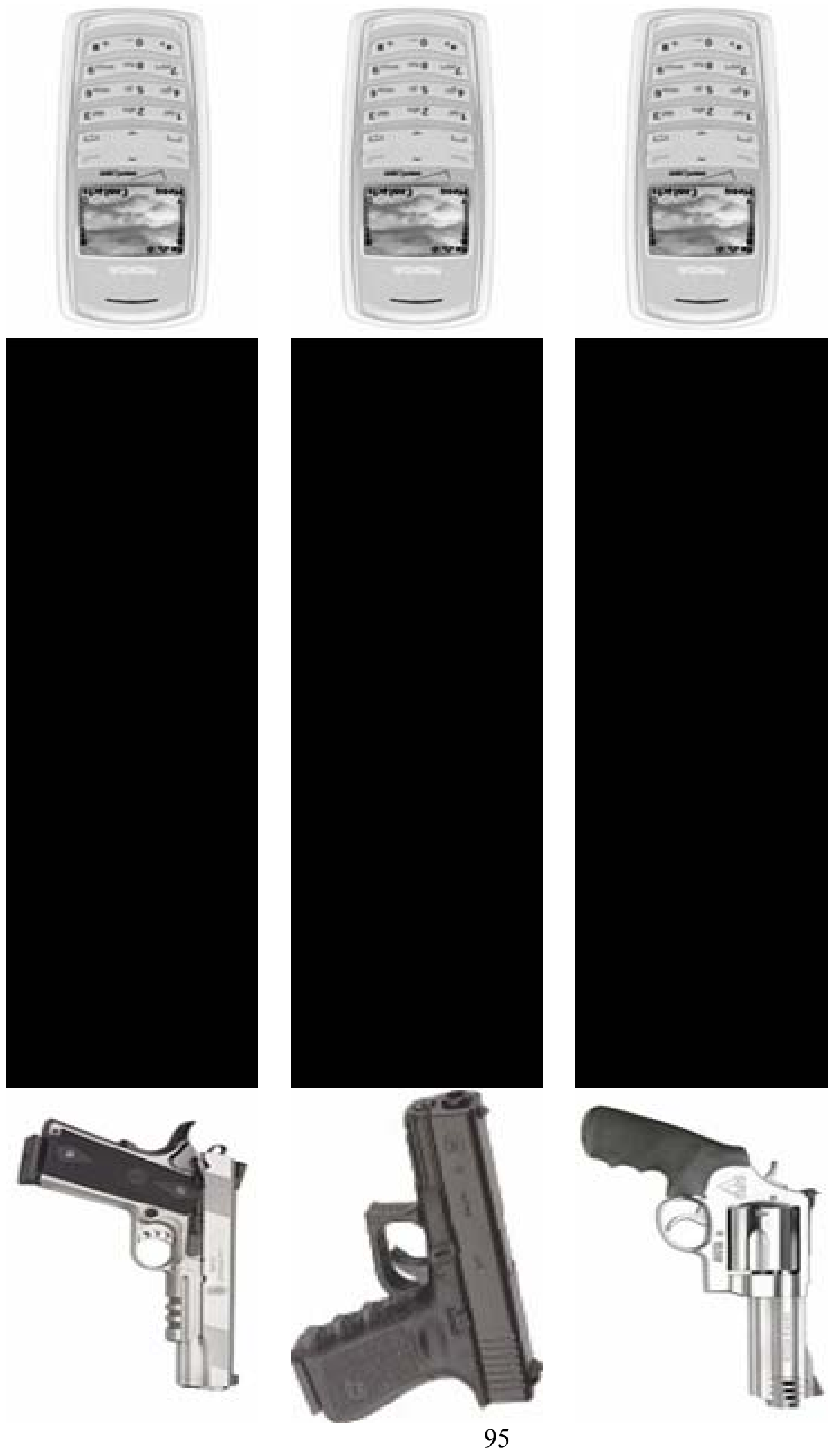



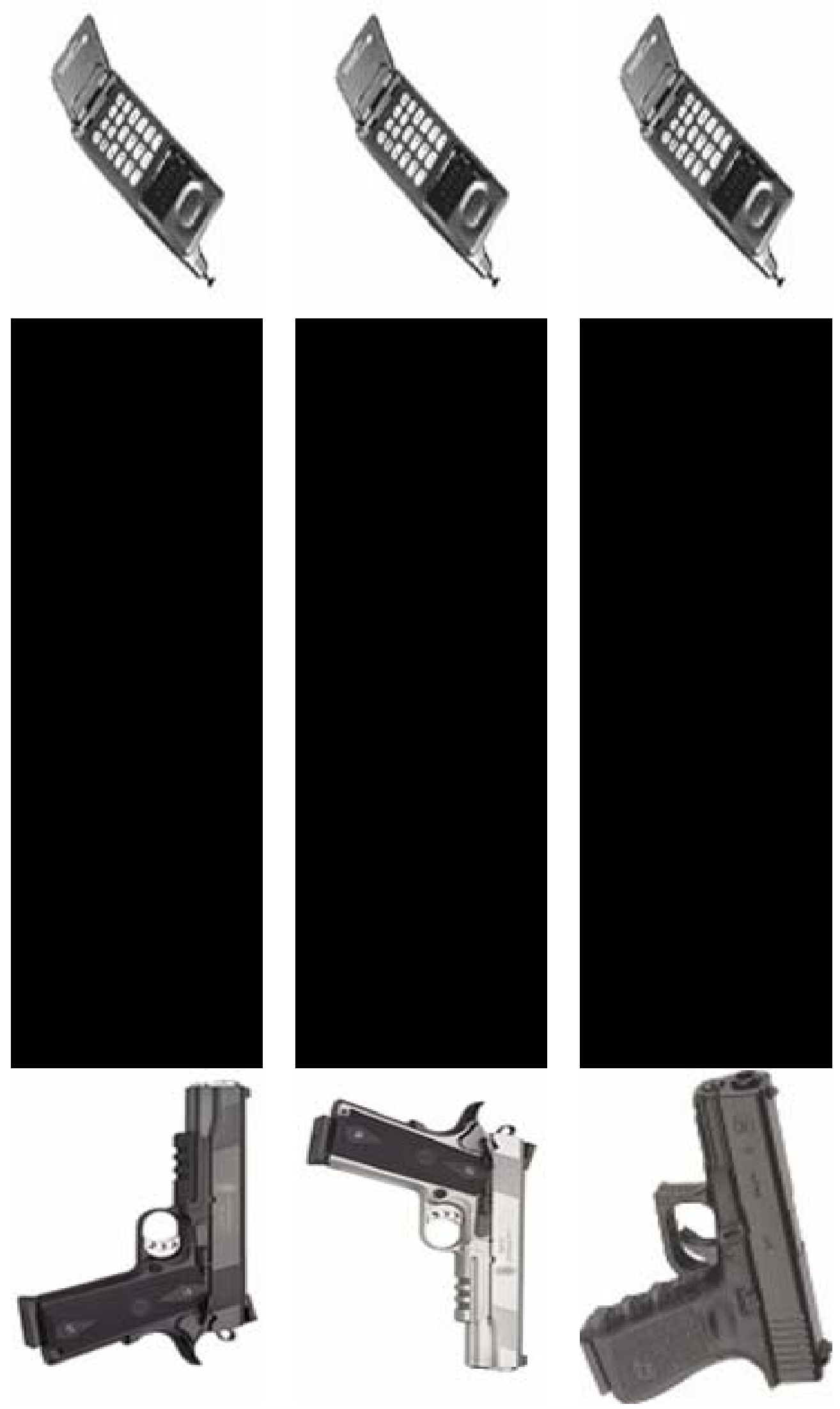

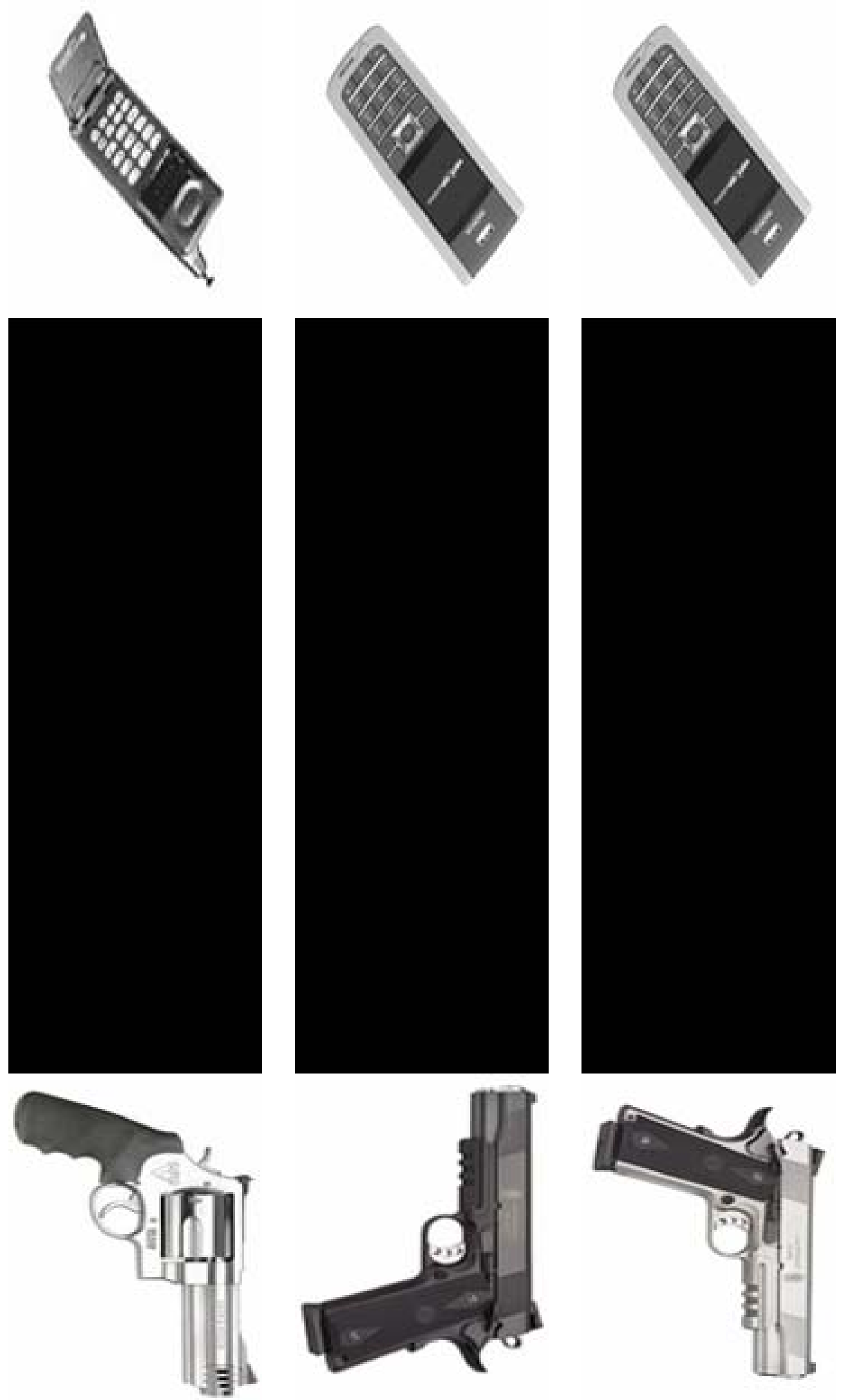
